Document downloaded from:

http://hdl.handle.net/10251/165525

This paper must be cited as:

Garrido, A.; Antonelli, L.; Martin, J.; Alemany Díaz, MDM.; Mula, J. (2020). Using LEL and scenarios to derive mathematical programming models. Application in a fresh tomato packing problem. Computers and Electronics in Agriculture. 170:1-14. https://doi.org/10.1016/j.compag.2020.105242

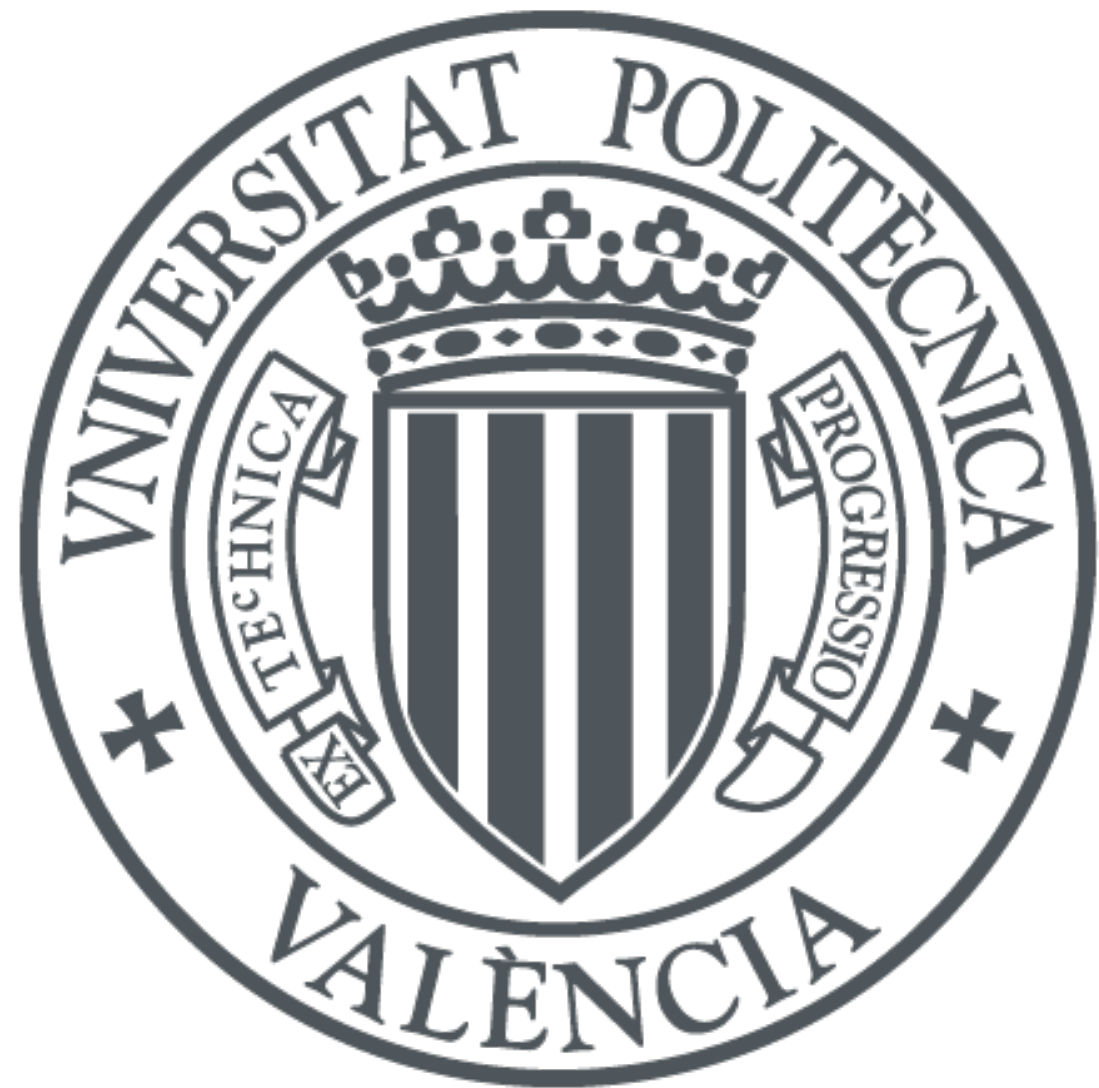

The final publication is available at

https://doi.org/10.1016/j.compag.2020.105242

Copyright Elsevier

Additional Information 


\title{
Using LEL and scenarios to derive mathematical programming models. Application in a fresh tomato packing problem
}

\author{
Alejandra Garrido ${ }^{\mathrm{a}, \mathrm{b}}$, Leandro Antonelli ${ }^{\mathrm{a}}$, Jonathan Martin ${ }^{\mathrm{a}}$, M.M.E. Alemany ${ }^{\mathrm{c}}$, ${ }^{*} \mathrm{Josefa}_{\text {Mula }}{ }^{\mathrm{c}}$ \\ ${ }^{a}$ LIFIA, Fac. de Informática, Univ. Nac. de La Plata, La Plata, Argentina, garrido@lifia.info.unlp.edu.ar, \\ lanto@lifia.info.unlp.edu.ar,jonathan.martin@lifia.info.unlp.edu.ar, \\ ${ }^{\mathrm{b}}$ CONICET, Argentina \\ ${ }^{\mathrm{c}}$ Research Centre on Production Management and Engineering (CIGIP), Universitat Politècnica de València, Valencia, Spain, \\ mareva@cigip.upv.es, ${ }^{*}$ Corresponding author: fmula@cigip.upv.es
}

\begin{abstract}
Mathematical programming models are invaluable tools at decision making, assisting managers to uncover otherwise unattainable means to optimize their processes. However, the value they provide is only as good as their capacity to capture the process domain. This information can only be obtained from stakeholders, i.e., clients or users, who can hardly communicate the requirements clearly and completely. Besides, existing conceptual models of mathematical programming models are not standardized, nor is the process of deriving the mathematical programming model from the concept model, which remains ad hoc. In this paper, we propose an agile methodology to construct mathematical programming models based on two techniques from requirements engineering that have been proven effective at requirements elicitation: the language extended lexicon (LEL) and scenarios. Using the pair of LEL + scenarios allows to create a conceptual model that is clear and complete enough to derive a mathematical programming model that effectively captures the business domain. We also define an ontology to describe the pair LEL + scenarios, which has been implemented with a semantic mediawiki and allows the collaborative construction of the conceptual model and the semi-automatic derivation of mathematical programming model elements. The process is applied and validated in a known fresh tomato packing optimization problem. This proposal can be of high relevance for the development and implementation of mathematical programming models for optimizing agriculture and supply chain management related processes in order to fill the current gap between mathematical programming models in the theory and the practice.
\end{abstract}

Keywords: Language extended lexicon (LEL); scenarios; software engineering; mathematical programming; fresh tomato packing.

\section{Introduction}

There is an increasing interest in mathematical programming models for optimal decision support applications (Dominguez-Ballesteros et al., 2002). Indeed, the development of optimization and decision support tools is needed to obtain all the benefits of transactional information technology (IT), improving the economic performance and customer satisfaction of supply chains (Grossmann, 2005). Along these lines, mathematical programming models have been demonstrated to be powerful optimization tools to support decision makers in many supply chain processes such as: production planning (Alemany et al., 2013), order promising (Alemany et al., 2018; Grillo et al., 2017), shortage planning (Esteso et al., 2018), supply chain production and transport planning (Mula et al., 2010), among others. The agriculture sector also faces many 
complex problems for optimization (Saranya \& Amudha, 2017) as it has been reported in some recent works (Cid-Garcia \& Ibarra-Rojas, 2019; Grillo et al., 2017; Liu et al., 2019). Some revisions about mathematical programming models applied to different problems in agriculture can be found for supply chain design (Esteso, Alemany, \& Ortiz, 2018), fresh fuit supply chain management (Soto-Silva et al., 2016), agribusiness supply chain risk management (Behzadi et al., 2018) and crop planning (Jain et al., 2018), among others.

Once formulated, mathematical programming models are often implemented as part of a decision support system (DSS), which is thus called model-driven DSS. We refer readers to the work of Udias et al. (2018) regarding an example of recent agricultural model-based DSS. These types of DSSs allow the user to make what-if analysis and define different scenarios without the need to understand the complexities of mathematical programming models (Mundi et al., 2013). Mir et al. (2015) provide an extensive revision of DSS application in agriculture noting their main weaknesses, most of them related to the poor involvement of stakeholders in the DSS construction process, which our methodology aims to overcome: failure to support stakeholder participation before and after development stages, failure to support the relationship between stakeholders and experts/developers, low adaptation, complexity with user inputs and under-definition of end users. Moreover, the construction of mathematical programming models is a complex and very timeconsuming process, which requires an expert to acquire a deep understanding of the modelling domain, context of use, decision making activity, and to learn the complete set of constraints from

61 the problem under study. All this problem knowledge should be acquired before the model is constructed, because any change that occurs afterwards might imply a whole redesign and implementation of the model. For this reason, mathematical programming model construction should be preceded by a conceptual modelling activity whose natural use in the field of applied mathematics has been pointed out by Lesh (1981) and Lesh et al. (1983). 
66 During conceptual modelling, different tools are used, like Bizagi, BPWin, iGrafx, Process

67 Modeler, System Architect and Visio, to help understand the domain, the flow of data, products, decisions and the interaction among parties, and to elicit requirements as completely as necessary (Armengol et al., 2015; Giannoccaro \& Pontrandolfo, 2001; Hernández et al., 2008; Mula et al., 2006; Pérez Perales et al., 2012). However, there has been no consensus or standardization in this regard.

The process of creating a conceptual model may be closely compared with the process of requirements elicitation for any software system. In particular, we claim that a very important aspect of conceptual models is that they should allow their iterative, incremental and collaborative construction. Indeed, agile methods in requirements engineering have demonstrated the importance of managing the inherent complexity of a system specification in an incremental and iterative manner (Schön et al., 2017). A relevant technique to elicit requirements and get a clear and complete understanding of a domain is the use of scenarios (Leite et al., 2000). The description of scenarios ranges from visual (storyboards) to narrative (structured text) (Young, 2004). They are constructed iteratively on the basis of a universe of discourse (UofD), i.e., a domain's vocabulary or lexicon. Leite and Franco (1993) named it the language extended lexicon (LEL). It is a meta-language used to gather or elicit requirements, which aims at describing the meaning of words and phrases specific to a given application domain. It has three convenient characteristics in the context of analytical modelling: easy to learn (Cysneiros \& Leite, 2001), easy to use (Gil et al., 2000) and good expressiveness (Kaplan et al., 2000). Moreover, there exist specific rules to derive LEL elements into scenario elements, and scenarios retrofit LEL's vocabulary in a very incremental and iterative construction process (Leite et al., 2000). Here, we claim that the above quality characteristics and the construction process of the pair LEL + scenarios make them an adequate conceptual model from where mathematical programming models could be systematically derived. 
91 In this article, we propose a novel methodology to guide the derivation of mathematical programming model elements from a conceptual model created with LEL + scenarios. Our derivation proposal consists of several rules that map conceptual model elements (either LEL vocabulary items or scenario elements previously derived from LEL) into mathematical programming model elements. The added benefit of this methodology is that it provides traceability from vocabulary and requirements specification to each mathematical programming model element. This traceability becomes very important when a change is necessary in the conceptual model, to know the particular place in the mathematical programming model specification where the change will have an impact.

100 In order to give further support to the derivation process, we relate conceptual model creation to a

101 knowledge building process of collective creation between stakeholders and analysts. This process emphasizes the production and continuous improvement of knowledge parts (Moskaliuk et al., 2009), and it is usually supported with a web-based knowledge building community like a mediawiki (Baraniuk et al., 2004). Thus, we have constructed a semantic mediawiki based on an

105 ontology for the collaborative creation of the conceptual model based on LEL and scenarios.

106 Moreover, the semantic mediawiki is used to semi-automatically derive mathematical 107 programming models.

108 Thus, the paper proposes a novel methodology that connects the areas of requirements engineering 109 and agile methods with conceptual modelling in order to create mathematical programming 110 models that capture the agriculture research domain more effectively and completely. 111 Summarizing, the main contributions of this paper are: (i) a proposal for utilizing the pair LEL + 112 scenarios to create conceptual models that gather the vocabulary of decision makers and specify 113 the domain knowledge necessary to build a mathematical programming model; (ii) a rule-based 114 methodology for the systematic derivation of mathematical programming models from the 115 conceptual model generated by LEL + scenarios; (iii) a knowledge model designed over an 
116 ontology based on the description of LEL + scenarios; and (iv) an extensible tool consisting of a

117 semantic mediawiki that allows to partially automate the mathematical modelling derivation. To

118 the best of our knowledge, the methodology proposed in this article is the first approach to

119 standardize the development of a conceptual model and its consequent translation to a

120 mathematical programming model, and no other requirement elicitation method in the field of

121 software engineering has been adapted for the derivation of mathematical programming models.

122 Moreover, the derivation process provides traceability from requirements to mathematical

123 programming model elements to deal with changes more effectively.

124 The rest of the paper is organized as follows. Section 2 provides a literature review on

125 mathematical programming models, conceptual models, requirements elicitation, LEL and

126 scenarios and knowledge building. Section 3 describes our methodology for the systematic

127 derivation of mathematical programming model elements from the conceptual model generated

128 by LEL+ scenarios. Section 4 applies the method to derive a linear mathematical programming

129 model for fresh tomato packing. Section 5 defines an ontology for LEL + scenarios on which we

130 based the construction of a semantic mediawiki for the semi-automatic derivation of the

131 mathematical programming model. Section 6 provides conclusions and future research directions.

\section{2. Literature review}

\section{$133 \quad 2.1$ Mathematical programming models}

134 Mathematical programming involves finding the values of some variables that, subject to certain

135 constraints, maximize or minimize an objective function. We assume that deterministic

136 mathematical programming models have a generic structure: a definition part and a modelling part

137 (Pérez et al., 2010; Shapiro, 1993). Table 1 provides a description of mathematical programming

138 model parts.

$139 \quad 2.2$ Conceptual mathematical modelling 
140 Siau (2004) defines conceptual modeling as the process of formally documenting a problem

141 domain to achieve understanding and communication between the different participants.

142 Developing conceptual models means specifying the essential objects, or components, of the

143 system to be studied, and the relationships or types of exchanges between the objects that affect

144 the functioning of the system (Lezoche et al., 2012). From the abstraction of conceptual models

145 emerges the concept of reference models, which are generic conceptual models that formalize

146 recommended practices for a given domain (Pesic \& van der Aalst, 2005).

147 Table 1. Mathematical programming model parts.

\begin{tabular}{|c|c|c|c|}
\hline $\begin{array}{l}\text { MATHEMATICAL } \\
\text { PROGRAMMING } \\
\text { MODEL PART }\end{array}$ & ELEMENT & DESCRIPTION & EXAMPLES \\
\hline \multirow[t]{4}{*}{ Definition part } & Indexes & $\begin{array}{l}\text { Objects or concepts of the model. The number of } \\
\text { elements of a class of objects provides the number } \\
\text { of instances of this class }\end{array}$ & $\begin{array}{l}\text { Machines }(m) \\
\text { Products }(i)\end{array}$ \\
\hline & Sets & $\begin{array}{l}\text { Group of instances of one or several indexes that } \\
\text { meet certain characteristics or constraints }\end{array}$ & $\begin{array}{l}\text { Group of products that can be } \\
\text { processed by each machine } P(m)\end{array}$ \\
\hline & Parameters & $\begin{array}{l}\text { Known characteristics of one or several elements } \\
\text { (indexes) over which is not possible to act }\end{array}$ & $\begin{array}{l}\text { Capacity of each machine }\left(\mathrm{Cap}_{m}\right) \\
\text { Production cost for each product on } \\
\text { each machine }\left(P C_{i m}\right)\end{array}$ \\
\hline & $\begin{array}{l}\text { Decision } \\
\text { variables }\end{array}$ & $\begin{array}{l}\text { Unknown characteristics of one or several } \\
\text { elements (indexes) over which it is possible to act } \\
\text { (decision-maker can determine their value) }\end{array}$ & $\begin{array}{l}\text { Quantity to be produced of each } \\
\text { product on each machine every time } \\
\text { period }\left(X_{i m t}\right)\end{array}$ \\
\hline \multirow[t]{2}{*}{ Modelling part } & $\begin{array}{l}\text { Objective } \\
\text { function }\end{array}$ & Goal/s to be optimized (minimize or maximize) & $\begin{array}{l}\text { Maximize profits } \\
\text { Minimize costs } \\
\text { Minimize time }\end{array}$ \\
\hline & Constraints & $\begin{array}{l}\text { Problem limitations that should be respected for } \\
\text { every combination of the decision variables }\end{array}$ & $\begin{array}{l}\text { Availability of resources (e.g. } \\
\text { machines' capacity) } \\
\text { Company policies (e.g. service level) } \\
\text { Logic or implicit constraints (e.g. } \\
\text { flow balance, positive quantities) }\end{array}$ \\
\hline Decision-maker & $\begin{array}{l}\text { Decision- } \\
\text { maker }\end{array}$ & Person who makes the decision & Planner, manager \\
\hline \multirow[t]{3}{*}{$\begin{array}{l}\text { Temporal } \\
\text { characteristics }\end{array}$} & Time-horizon & $\begin{array}{l}\text { The length of time (with a beginning and end date) } \\
\text { over which a problem is optimized }\end{array}$ & A year, six months, etc. \\
\hline & Time-period & Space of time into which a time-horizon is divided & $\begin{array}{l}\text { Seconds, minutes, hours, days, } \\
\text { weeks, months or years }\end{array}$ \\
\hline & $\begin{array}{l}\text { Replanning } \\
\text { time period }\end{array}$ & Space of time in which the plan is calculated again & $\begin{array}{l}\text { Seconds, minutes, hours, days, } \\
\text { weeks, months or years }\end{array}$ \\
\hline
\end{tabular}

149 In the field of conceptual mathematical modelling, Schneeweiss (2003a) identifies different

150 classes of distributed decision making (DDM) problems in supply chain management. The same

151 author derives the coupling equations for the most usual cases in coordinating the supply chain

152 (Schneeweiss, 2003b). However, the coupling equations are still of a very general, almost verbal

153 character. In this context, Alemany et al. (2007) propose a reference mathematical programming 
model for collaborative planning that addresses two of the challenges of DDM: the spatial and temporal interdependencies. Alemany et al. (2011) developed an application to support the integrated modelling and execution of the supply chain collaborative planning process made up of several decisional centers which make decisions based on mathematical programming models.

158 However, the formulation of the own specific decisional characteristics of each decision center 159 (micro-decision view) mainly relies on the ability of the mathematical programming modeler. Moreover, Pérez-Perales et al. (2012) propose a framework to support modelling the decisional view of collaborative planning through mathematical programming models.

While the above studies are very useful, this article provides further tool-supported guidence and a precise specification in terms of derivation rules to derive mathematical programming models from a conceptual model, as opposed to general descriptions or relying in the modeler's ability.

\subsection{Process of mathematical programming model formulation}

Since conceptual models are not standardized, neither is the process of deriving the mathematical programming model from the concept model, which remains ad hoc. In this sense, Raghunathan (1996) proposed a methodology to design a DSS with its underlying mathematical programming and data models. The methodology includes six steps: (i) problem domain analysis, (ii) database design, (iii) modelbase design, (iv) database/modelbase integration design, (v) problem/decision maker characteristics and (vi) specific DSS design. However, the setting of Raghunathan (1996) is a classroom, so the problem statement is completely specified from the start. Alternatively, our proposal is inspired in the current, agile way of system specification, which recognizes that the construction of any model should be iterative and incremental. Additionally, the use of entityrelationship modelling by Raghunathan (1996) has two implications: a) the problem must be simple, otherwise the diagram is not even readable; and b) stakeholders may not be able to 
178 for the conceptual model, which is more appealing for a system specification that incorporates

179 stakeholders in the process.

180 Furthermore, Dominguez-Ballesteros et al. (2002) define different stages in the process of

181 deterministic and stochastic linear programming model formulation and implementation:

182 conceptualisation (data collection and study of the problem), data modelling (categorisation and

183 abstraction of the data), algebraic form (modeller's form), translation (matrix generator/modelling

184 language), machine-readable form (algorithm's form), solution and solution analysis. However,

185 the stages can be understood as guidelines for the mathematical programming modeler more than

186 a derivation procedure. That is, unlike Raghunathan (1996) and to the best of our knowledge, no

187 methodology or structured modeling language is proposed for the conceptualization stage.

\section{$188 \quad 2.4$ Requirements elicitation}

190 Requirements elicitation is the process that analysts follow to ensure a correct understanding of

191 stakeholders' needs and the domain specification before a system is designed and implemented

192 (Leite et al., 2000). In this regard, Geisser and Hildenbrand (2006) state that software requirements

193 are very complex and a multitude of stakeholders participate in their description (Geisser \&

194 Hildenbrand, 2006). They propose a method called CoREA that covers collaborative requirements

195 elicitation in a distributed environment as well as quantitative decision support for distributed

196 requirements prioritization and selection. Our proposed approach also relies on collaborative

197 knowledge acquisition and description, with the added advantage of using this knowledge base as

198 a conceptual model from where a mathematical programming model can be derived through the

199 application of a set of rules.

200 Closer to our work, Laporti et al. (2009) propose an approach to develop system requirements in

201 an iterative and collaborative way. Experts in the domain collaborate to build narrative

202 descriptions of stories. Then, these stories are used as input to describe scenarios, which are in

203 turn used to define use cases. In this regard, our proposal is similar since it considers the collective 
construction of LEL + scenarios and a mapping between LEL, scenarios and mathematical programming models. The difference is that the output of the transformation in the work by Laporti et al. (2009) is still a textual, semi-structured representation (use cases), which does not distance much of the previous products, whereas in our case the output is a structured mathematical programming model, so the mapping requires a more complex strategy that includes a precise representation of the relations among model elements. Our approach uses two existing techniques for requirements elicitation: the LEL (Leite \& Franco, 1993) and scenarios (Leite et al., 2000).

211 The LEL is a very convenient tool for both stakeholders with no technical skills and analysts, since

212 it conforms to the mechanism used by the human brain to organize knowledge (Oliveira et al., 213 2007), which makes it easy to learn while having good expressiveness. The process to build the 214 LEL is comprised of six steps (Breitman \& Leite, 2003; Kaplan et al., 2000), which allow constructing a list of terms classified in four categories (see Table 2).

216 Turning into scenarios, they can be used in different stages of software development, from 217 clarifying business processes and describing requirements to providing the basis of acceptance 218 tests (Alexander \& Maiden, 2004). Leite et al. (2000) propose a template with six elements to 219 describe scenarios (see Table 2), which are derived from the LEL following a methodology consisting of five steps: (i) to identify main and secondary actors, i.e., LEL symbols that belong to the subject type; (ii) to identify scenarios within the behavioral responses of symbols chosen as actors; (iii) to define the scenario goal based on the notion of the verb symbol in which the scenario is based; (iv) to identify the scenario resources, searching in the notion of the verb that created the scenario, for LEL symbols of the object category; and (v) to derive episodes from each behavioral response of the verb that identified the scenario.

Table 2. LEL categories and scenarios elements.

\begin{tabular}{llll}
\hline Category & Characteristics & Notion & Behavioral responses \\
\hline Subject & $\begin{array}{l}\text { Active elements which perform } \\
\text { actions }\end{array}$ & $\begin{array}{l}\text { Characteristics or condition } \\
\text { that subject satisfies }\end{array}$ & Actions that subject performs \\
\hline
\end{tabular}




\begin{tabular}{|c|c|c|}
\hline Object & $\begin{array}{l}\text { Passive elements on which } \\
\text { subjects perform actions }\end{array}$ & $\begin{array}{l}\text { Actions that are performed on } \\
\text { object }\end{array}$ \\
\hline Verb & $\begin{array}{l}\text { Actions that subjects perform } \\
\text { on objects }\end{array}$ & $\begin{array}{l}\text { Steps needed to complete the } \\
\text { action }\end{array}$ \\
\hline State & $\begin{array}{l}\text { Situations in which subjects } \\
\text { and objects can be located }\end{array}$ & $\begin{array}{l}\text { Actions that must be performed } \\
\text { to change into another state }\end{array}$ \\
\hline Attribute & \multicolumn{2}{|l|}{ Description } \\
\hline Title & \multicolumn{2}{|c|}{ Name that describes the scenario } \\
\hline Goal & \multicolumn{2}{|c|}{ Conditions and restrictions to be reached after the execution of the scenario } \\
\hline Context & \multicolumn{2}{|c|}{$\begin{array}{l}\text { Conditions and restrictions that are satisfied and constitute the starting point of the scenario } \\
\text { execution. }\end{array}$} \\
\hline Actors & \multicolumn{2}{|c|}{ Agents that perform actions during the scenario starting from the context to reach the goal } \\
\hline Resources & \multicolumn{2}{|c|}{ Products and elements used by the actors to perform actions } \\
\hline Episodes & \multicolumn{2}{|c|}{ Steps executed by the actors using the resources starting at the context to reach the goal } \\
\hline
\end{tabular}

227

228

229

230

231

232

233

234

235

236

237

238

239

240

241

242

243

244

\subsection{Ontologies and knowledge building}

Ontologies define the common vocabulary in which shared knowledge from a domain of discourse is represented (Gruber, 1993; 1995). They can be constructed in two ways, domain dependent and generic. CYC (Lenat, 1995), WordNet (G.A. Miller, 1995) and Sensus (Swartout et al., 1996) are examples of generic ontologies. A benefit of using a domain ontology is to attain the shared and agreed definition of a semantic model of domain data and the links between different types of semantic knowledge, which makes it suitable in formulating data searching strategies for information retrieval (Munir \& Sheraz Anjum, 2018).

Furthermore, a semantic mediawiki defined over an ontology provides a web-based support for a knowledge building community (Baraniuk et al., 2004). We have used a semantic mediawiki in this work to allow for the collaborative definition of LEL + scenarios of the problem domain and for the semi-automatic derivation of the mathematical programming model using the mediawiki's query engine.

\section{Methodology for mathematical programming model derivation}

\subsection{Conceptual model construction and methodology overview}

The mathematical programming model derivation process starts from an existing conceptual model consisting of a complete or close to complete specification of LEL + scenarios of the system. There are three variations that we propose to the original definition of LEL and scenarios 
247 for the specific goal of generating mathematical programming models. The first is that we do not 248 use the terms in the "state" category of the LEL, because no mathematical programming model 249 element is derived from them. The second is that we distinguish attributes inside the notion of 250 symbols, especially those that become scenario's actors and resources. That is, an actor is a LEL 251 subject, and as such it will have a notion with its conceptual definition. We call attributes to the 252 terms that characterize the actors and appear in their notion, usually after the verb "has". Similarly, a resource is a LEL object with a notion that names its attributes. In turn, attributes are also defined as LEL objects, and this is the reason that attributes are underlined in the notion of the actor or resource that they characterize, describing a relation between LEL terms. The third variation that we propose is related to specifying the temporal location inside scenarios' context element with more detail, identifying three fields: time horizon, time period and replanning time period. In order to provide a better understanding of the proposed methodology, Figure 1 depicts its two main stages (Conceptual model construction and Mathematical programming model construction), the phases in the construction process for each stage, and two different levels of iteration. There is one iteration cycle that occurs often in the construction of the conceptual model, where scenarios may retrofit the LEL, and a second level or global iteration cycle, between the conceptual model and the mathematical programming model, which should not be as usual. The methodology provides traceability by way of rules that specify the source of each mathematical programming model element. Therefore, this methodology is robust enough to actually afford changes in the mathematical programming model construction.

267 The input for the whole process, as Figure 1 shows, is the domain knowledge obtained from stakeholders and documents. The first phase consists in the LEL specification, which is created by a system analyst together with the stakeholders and, if possible, the expert in mathematical modelling, thus creating a multi-disciplinary team. They should identify the sources of knowledge,

271 define the LEL, verify and validate it. The second phase consists in specifying scenarios using the 
272 knowledge captured in the LEL. If during the description of the scenario, it is noticed that more

273 knowledge from the domain is needed, the process goes back to phase 1.

274 When the knowledge captured by the LEL + scenarios appears adequate and complete, the third 275 phase (Mathematical Programming Model Derivation) begins. This phase uses the knowledge 276 captured in LEL and scenarios to derive the mathematical model. The mathematical programming 277 derivation proposal consists of several rules that map conceptual model elements (either LEL 278 vocabulary items or scenario elements previously derived from LEL) into mathematical 279 programming model elements. The derivation process may be carried out manually by the 280 mathematical programming expert, possibly together with the system analyst. In addition, we 281 provide tool support for a semi-automatic derivation through a semantic mediawiki. Even with a 282 tool support, manual revision from the mathematical programming expert will be necessary, since 283 it is not possible to automatically create the equations that model constraints from a textual 284 description, although we can isolate the sentence that contains a constraint from the conceptual 285 model. In Fig. 1, the numbering of steps in the mathematical programming model derivation phase 286 denotes a sequence in which rules should be applied. Moreover, at the end of each of these steps, 287 the manual intervention of the mathematical programming expert is advised to prevent an overly 288 complex mathematical programming model (as it could happen with a large number of indexes) 289 or to spot missing items in the conceptual model. Furthermore, it could also be detected that more 290 knowledge from the LEL and Scenarios is needed, and it that case, the process goes back to the 291 conceptual model construction. 


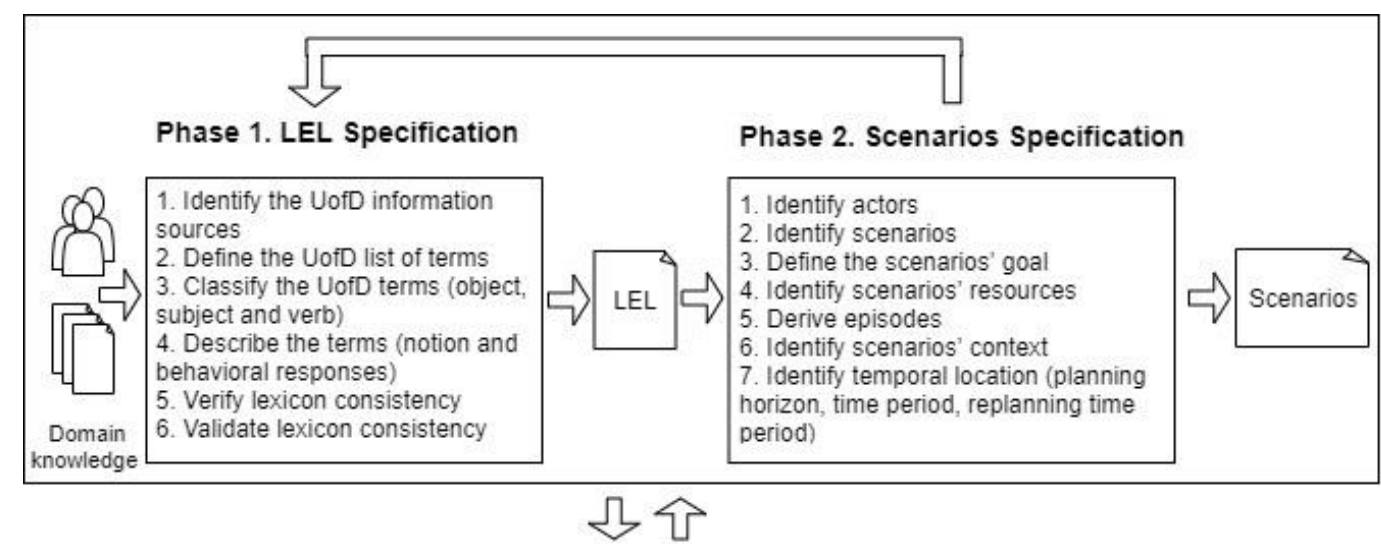

Stage 1.

Conceptual

model

construction

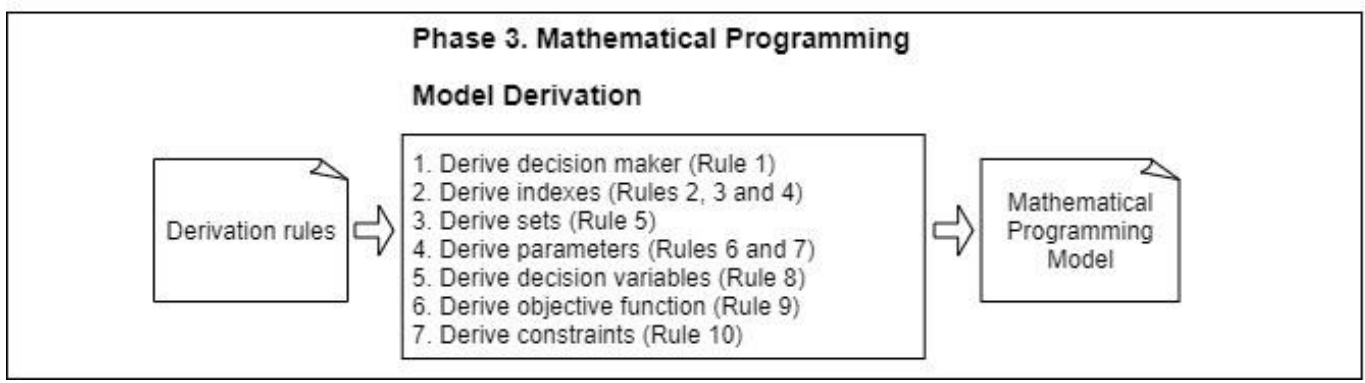

Stage 2.

Mathematical

model

construction

Fig. 1. Methodology for mathematical programming model derivation.

\subsection{Mathematical programming model derivation}

This section presents the rules that allow deriving a mathematical programming model from a derivation rule, listed by its rule number. Note that rule numbers do not dictate an order of application except for the order dictated by the methodology and outlined in Figure 1. Following this description, Table 3 provides a summary of the rules.

Rule 1. The main actor of the base scenario becomes the decision maker in the mathematical

304 Main actors are those who execute actions in the domain, in this case, those making decisions.

305 We consider the main actors to be a single person or several persons playing the same role, i.e., 306 making a centralized decision. There will be a base scenario that derives from the behavioral

307 response of the single main actor, who will be the decision maker in the mathematical programming model. 

context of the base scenario, becomes an index of the mathematical programming model.

311 Moreover, other data objects related to time in the temporal location could also become 312 indexes.

313 The base scenario should specify the temporal location in its context attribute. Particularly, the

314 time period specifies the regular intervals in the time horizon at which different decisions are to 315 be made. If such time period exists, Rule 2 is applied to derive an index from it. Other LEL objects 316 specifying time considerations (shipping day or maturity day, among others) could also appear in

317 the temporal location and probably become indexes.

318 Rule 3. Scenarios' actors that have multiple instances become indexes of the mathematical 319 programming model

320 Actors in scenarios are derived from LEL subjects. A subject in LEL could denote a specific 321 person or a role. If it is a role, which is filled by several persons, there should be an index in the 322 mathematical programming model to represent them. If the cardinality of a particular actor is likely 323 to grow from 1 into several people, the mathematical programming expert could decide to include 324 the index to make the model more flexible to accommodate this change in the near future.

325 Rule 4. Scenarios' resources that have multiple instances become indexes of the 326 mathematical programming model

Resources represent relevant physical elements or information used by scenarios' actors to achieve their goal. Resources derive from LEL's objects. Objects can be singletons (a single instance) or denote a class of elements. When an object denotes a class, it becomes an index of the mathematical programming model. Similar to Rule 3, if the object could grow into a class in the future, the mathematical programming expert could decide to include the index. 
334 Two or more actors and/or resources are related when they appear in the same notion. In the case where the relation among them is restricted for some cases, this restriction should be defined as a set. Conversely, if the relation is many-to-many, it would not be necessary to define the sets.

Rule 6. The number of instances of the indexes could become parameters in the mathematical programming model

An actor that becomes an index derives from a LEL subject with multiple instances. The number of instances of an index is known, and therefore, it could become a parameter of the mathematical programming model, although this is not always the case. The same occurs with resources and temporal data objects. An example is the number of instances of the time period, which matches the decision time horizon and could be defined as a parameter.

Rule 7. Attributes of scenarios' actors and attributes of scenarios' resources and attributes of their relationship with known values become parameters of the mathematical programming model. Each parameter is indexed by those indexes related to it by the same notion and for which its value remains known

In the case of attributes that did not become indexes by Rule 4 and denote a known value, by this rule they become parameters of the mathematical programming model. Moreover, a parameter derived by this rule should be indexed by the indexes that are related to it. We define two LEL terms as related if they appear in the same notion, i.e., either one of them appears in the notion of the other, or both terms appear in the notion of a third term. These indexes could include other actors but also other resources. However, note that not all indexes that appear in the notion will be assigned to the parameter, only those that refer to a known value. Thus, the mathematical programming expert should determine which subset of indexes refers to a known value, and the 
parameter should be indexed only by that subset of indexes. The notion gives the whole subset, but the expert decides what indexes should be used.

Rule 8. Attributes of scenarios' actors and attributes of scenarios' resources and attributes of their relationship that have unknown values become decision variables of the mathematical programming model. Each decision variable is indexed by those indexes related to it by the same notion and for which its value is unknown

362 This rule is similar to Rule 7 but for unknown values. That is, attributes that appear in the notion of actors or resources, which values should be assigned in the decision process, become decision variables. Moreover, decision variables should take the indexes that are related to it by the same notion and refer to unknown values. It could be necessary to define artificial decision variables

366 (without economic/physical interpretation) in order to mathematically represent a reality or to 367 force some logical constraint.

368 Rule 9. The goal of the base scenario contains the objective function

The base scenario should specify in its goal attribute, the purpose of the main actor (which becomes the decision maker by Rule 1) in executing the scenario. This goal is specified as a complex sentence with a relative clause that starts with "so as to" followed by the verb "minimize" or "maximize". From this verb to the end, this relative clause becomes the objective function.

373 Moreover, the expert may look for further details of each objective function in the notion of the

374 LEL symbols involved in the goal.

375 Rule 10. The set of context sentences of all scenarios become the set of constraints of the mathematical programming model

377 Scenarios should specify in its context attribute, the conditions to comply. These conditions are 378 described in natural language, as sentences that relate to the actors and resources of each scenario. 
379 Experts in mathematical programming modeling should use the restrictions described in the

380 scenarios' context and relate them to parameters and indexes previously defined by other rules to

381 derive the set of mathematical programming model constraints. These constraints usually contain

382 logical constraints that represent business rules. These rules should appear during the requirements

383 elicitation that a system analyst carries out to construct the LEL, and therefore they would also be

384 derived as part of the scenarios' context. Additionally, there are added other artificial constraints

385 (for instance, a positive boundary to variables) in order to avoid erroneous results. These

386 constraints will not generally appear in the conceptual model and they should be added by a

387 subsequent analysis of the mathematical programming expert.

388 Table 4 summarizes the relationship among LEL, scenarios and mathematical programming model

389 elements. Rules are grouped by the mathematical programming model element that is derived from

390 them. The second and third columns use indentation to represent nested concepts (for example, in

391 Rule \#2, the scenario element that generates an "Index" is the "Time period", inside the "Temporal

392 location", which is in the "Context" of the "Base scenario").

393 Table 3. Equivalences among LEL, scenario and mathematical programming model elements.

\begin{tabular}{|c|c|c|c|}
\hline $\begin{array}{l}\text { Rule } \\
\text { Number }\end{array}$ & LEL model & Scenario model & $\begin{array}{l}\text { Mathematical } \\
\text { model }\end{array}$ \\
\hline 1 & Subject & $\begin{array}{l}\text { Base scenario } \\
\text { Main actor }\end{array}$ & Decision Maker \\
\hline 2 & Object & $\begin{array}{l}\text { Base scenario } \\
\text { Context } \\
\text { Temporal location } \\
\text { Time period }\end{array}$ & Index \\
\hline 3 & $\begin{array}{l}\text { Subject } \\
\text { (multiple instances } \\
\quad \text { or single instance--opt) }\end{array}$ & $\begin{array}{l}\text { Any scenario } \\
\text { Actor }\end{array}$ & Index \\
\hline 4 & $\begin{array}{l}\text { Object } \\
\quad \text { (multiple instances } \\
\quad \text { or single instance--opt) }\end{array}$ & $\begin{array}{l}\text { Any scenario } \\
\text { Resource }\end{array}$ & Index \\
\hline 5 & $\begin{array}{l}\text { Subject / Object } \\
\text { Notion } \\
\text { (restriction) }\end{array}$ & $\begin{array}{l}\text { Any scenario } \\
\text { Actor / Resource }\end{array}$ & Set \\
\hline 6 & $\begin{array}{l}\text { Subject / Object } \\
\text { Notion } \\
\quad \text { (no. of instances) }\end{array}$ & $\begin{array}{l}\text { Any scenario } \\
\text { Actor / Resource (index) }\end{array}$ & Parameter \\
\hline 7 & $\begin{array}{l}\text { Subject / Object } \\
\text { Attribute (known value) }\end{array}$ & $\begin{array}{l}\text { Any scenario } \\
\text { Actor / Resource }\end{array}$ & Parameter \\
\hline
\end{tabular}




\begin{tabular}{llcc}
\hline & & Attribute & \\
\hline $\mathbf{8}$ & Subject / Object & Any scenario & Decision Variable \\
& Attribute (unknown value) & $\begin{array}{c}\text { Actor / Resource } \\
\text { Attribute }\end{array}$ & \\
\hline $\mathbf{9}$ & Subject & Base scenario & Objective function \\
& Behavioral response & Goal & \\
& Object & Any context & Constraint
\end{tabular}

\section{Application}

395 This section applies the above methodology to the problem of fresh tomato packing addressed by

396 Miller et al. (1997). The purpose of using an existing problem is to contrast the result of our

397 derivation rules with a real, published mathematical programming model while avoiding the long

398 description that a new mathematical program would require.

\section{4.1 Conceptual model of the tomato packing problem: LEL + scenarios}

400 This section presents the conceptual model for the tomato packing problem created in terms of

401 LEL + scenarios. The team assembled for this task was multidisciplinary, that is, composed of 402 system analysts and a mathematical programming expert. The information sources of the UofD to 403 construct the LEL were provided by the article from Miller et al. (1997), interviews with local 404 tomato producers that played the role of customers and other documentation sources online. After 405 three iterations, the team arrived at the LEL that appears in Table 4.

406 Table 4. LEL of the tomato packing problem.

\begin{tabular}{lll}
\hline Term & Role & Notion \\
\hline $\begin{array}{l}\text { Packinghouse } \\
\text { management }(\mathbf{P M})\end{array}$ & Subject & $\begin{array}{l}\text { Conducts the business of the packinghouse. The PM decides when to harvest tomatoes } \\
\text { matured in the present or previous cycle, communicates its decision to growers and packs } \\
\text { the harvested tomatoes to fulfil the market demand }\end{array}$ \\
\hline Grower & Subject & $\begin{array}{l}\text { Person responsible for a tomato field (has been assigned a certain number of acres of } \\
\text { tomatoes), including harvesting the tomatoes, for which it has some harvest capacity. } \\
\text { There are several growers. Each grower produces a certain yield of bins of tomatoes per } \\
\text { acre to take them to the packinghouse }\end{array}$ \\
\hline Market & Subject & $\begin{array}{l}\text { Customers of the packinghouse, who buy tomatoes to sell them. The market has a market } \\
\text { demand in number of boxes of tomatoes they would like to buy each day }\end{array}$ \\
\hline Acres of tomatoes & Object & $\begin{array}{l}\text { Land assigned to a grower with tomatoes that get matured on a certain maturity day, and } \\
\text { are harvested on a certain harvesting day. Acres may have a fraction of "vine ripe } \\
\text { tomatoes" that are sold "as is" }\end{array}$ \\
\hline Tomato & Object & $\begin{array}{l}\text { Produce planted by growers on the acres of their fields. Tomatoes that have not been } \\
\text { harvested in 2 cycles generate a cost of damaged tomato }\end{array}$ \\
\hline Harvesting day & Object & $\begin{array}{l}\text { Day in which tomatoes already matured are harvested. Every day in the horizon may be } \\
\text { a harvesting day }\end{array}$ \\
\hline Maturity day & Object & $\begin{array}{l}\text { Day in a period in which tomatoes in an acre get ready to be harvested. The acres of a } \\
\text { specific grower may have different maturity days within the decision horizon }\end{array}$ \\
\hline
\end{tabular}




\begin{tabular}{|c|c|c|}
\hline Decision horizon & Object & $\begin{array}{l}\text { Largest time in which the readiness of tomato fields for harvest can be accurately } \\
\text { predicted. It is } 3 \text { days }\end{array}$ \\
\hline Harvest capacity & Object & The capacity of a grower to harvest during a certain day \\
\hline Bin & Object & Container where the grower places the harvested tomatoes \\
\hline Cost of damaged tomato & Object & $\begin{array}{l}\text { Penalty cost due to dissatisfaction of a grower because of delayed harvest of fields } \\
\text { matured in the previous and present cycles in } \$ \text { per bin }\end{array}$ \\
\hline $\begin{array}{l}\text { Fraction of "vine ripe } \\
\text { tomatoes" (v.r.t.) }\end{array}$ & Object & Tomatoes sold without gassing \\
\hline $\begin{array}{l}\text { Yield of bins of tomatoes } \\
\text { per acre }\end{array}$ & Object & The number of bins of harvested tomatoes per acre of a certain grower \\
\hline Packinghouse & Object & $\begin{array}{l}\text { Place where tomatoes are packed in boxes and stored. It has a packing capacity, and a } \\
\text { gassing capacity per day. The packinghouse requires some fraction of hour needed to } \\
\text { pack a bin at a certain packing cost. The packinghouse generates a fraction of tomatoes } \\
\text { ready after gassing. The packinghouse works on regular hours ( } 9 \text { to } 5 \text { ) and overtime hours } \\
\text { (after } 5 \mathrm{pm} \text { ) to generate an inventory level at the end of the day }\end{array}$ \\
\hline Packing cost & Object & $\begin{array}{l}\text { The total packing cost consist of: (1) cost of damaged tomatoes; (2) inventory holding } \\
\text { cost, (3) shortfall cost, (4) overtime and (5) regular hour packing costs }\end{array}$ \\
\hline Packing capacity & Object & No more tomatoes may be packed once the packinghouse reaches the packing capacity \\
\hline Gassing capacity & Object & $\begin{array}{l}\text { Capacity of the packinghouse to gass tomatoes in a harvesting day. It is measured in } \\
\text { number of boxes of tomatoes }\end{array}$ \\
\hline $\begin{array}{l}\text { Fraction of hour needed } \\
\text { to pack a bin }\end{array}$ & Object & Time required for packing 1 bin of harvested tomatoes and put them in boxes \\
\hline $\begin{array}{l}\text { Fraction of tomatoes } \\
\text { ready after gassing }\end{array}$ & Object & Tomatoes ready after a gassing session \\
\hline Regular packing hours & Object & $\begin{array}{l}\text { Hours when the packinghouse is operating on a day, that generates a regular packing } \\
\text { cost. It goes from } 9 \text { am to } 5 \mathrm{pm}\end{array}$ \\
\hline Overtime packing hours & Object & $\begin{array}{l}\text { Extra hours required to complete the packing at the packinghouse on a day. They } \\
\text { generate a higher cost than the regular packing hours. Overtime hours are after } 5 \mathrm{pm}\end{array}$ \\
\hline Regular packing cost & Object & Cost of packinghouse operation in $\$$ per hour during regular packing hours \\
\hline Overtime packing cost & Object & Cost of packinghouse operation in $\$$ per hour during overtime packing hours \\
\hline Inventory level & Object & $\begin{array}{l}\text { Number of boxes of tomatoes of the packinghouse at the end of a certain day. It has a } \\
\text { certain inventory holding cost in box/day }\end{array}$ \\
\hline Inventory holding cost & Object & Cost of packinghouse storage in boxes/day \\
\hline Market demand & Object & $\begin{array}{l}\text { Number of boxes of tomatoes that the packinghouse customers require in each harvesting } \\
\text { day. If the market demand is not covered it generates a shortfall }\end{array}$ \\
\hline Shortfall & Object & $\begin{array}{l}\text { Number of missing boxes of tomatoes needed to reach the market demand on a certain } \\
\text { harvesting day }\end{array}$ \\
\hline Shortfall cost & Object & Cost of being short on satisfying the market demand in $\$$ per box short \\
\hline Box & Object & Container where tomatoes are placed during packing \\
\hline Harvest & Verb & To cut the tomatoes that are matured \\
\hline Pack & Verb & $\begin{array}{l}\text { Put in boxes the harvested tomatoes. Packing is done on regular hours at a certain cost } \\
\text { or overtime hours to complete packing all harvested tomatoes }\end{array}$ \\
\hline Gass & Verb & $\begin{array}{l}\text { Technique used to ripen tomatoes that are not completely matured by exposing them to } \\
\text { ethylene gas }\end{array}$ \\
\hline
\end{tabular}

408 The first version of the scenarios was created after the first iteration of the LEL and was used to

409 retrofit the second iteration of the LEL.

410 The following four tables describe the scenarios of the tomato packing problem. First, Table 5

411 presents the sole Level 0 scenario, called base scenario. Then, Tables 6 through 8 show the three

412 scenarios of Level 1, which derive from episodes of the base scenario. 
414 Table 5. Scenario Level 0 of the tomato packing problem.

\begin{tabular}{|c|c|c|}
\hline Scenario 0: & \multicolumn{2}{|c|}{ Plan the harvest and the packing of fresh tomatoes } \\
\hline Goal & \multicolumn{2}{|c|}{$\begin{array}{l}\text { Make a plan at the beginning of the present cycle to harvest and pack tomatoes matured on the present and last } \\
\text { cycles, so as to minimize the total packing cost }\end{array}$} \\
\hline \multirow[t]{2}{*}{ Actors } & Main actor & Packinghouse management (PM) \\
\hline & Secondary actors & Growers, market \\
\hline \multirow[t]{2}{*}{ Resources } & Physical resources & $\begin{array}{l}\text { Packinghouse; acres of matured tomatoes for each grower in the present and past cycles; } \\
\text { tomatoes; bins; boxes. }\end{array}$ \\
\hline & $\begin{array}{l}\text { nformation } \\
\text { esources }\end{array}$ & $\begin{array}{l}\text { Market demand in number of boxes for each day in the present cycle; for each grower, the } \\
\text { number of acres of matured tomatoes in the present and past cycles and the number of bins } \\
\text { of tomatoes generated after harvesting. }\end{array}$ \\
\hline Context & \multicolumn{2}{|c|}{$\begin{array}{l}\text { - Not all tomatoes that get matured in a cycle are harvested in the same cycle. } \\
\text { - Tomatoes harvested in the next cycle after they get matured may be sold but have less quality. } \\
\text { - Tomatoes not harvested in the next cycle after they get matured must be discarded. } \\
\text { - A grower may only harvest up to their capacity. } \\
\text { - The packinghouse may only pack and gass a limited number of tomato boxes a day. } \\
\text { - Temporal location: } \\
\text { - Decision horizon: } 3 \text { days } \\
\text { - Decision period: harvesting day; every day in a decision horizon. } \\
\text { - Other temporal variables: maturity day; any day in the decision horizon. }\end{array}$} \\
\hline Episodes & \multicolumn{2}{|c|}{$\begin{array}{l}\text { - PM makes a plan with the harvesting day of matured tomatoes, for each day in the present cycle, in number of acres } \\
\text { for each grower. } \\
\text { - Each grower harvests the amount decided and communicated by the PM. } \\
\text { - Each grower takes the harvested tomatoes in bins to the packinghouse. } \\
\text { - PM packs the harvested tomatoes in the packinghouse, labelling some boxes as "vine-ripe tomatoes". } \\
\text { - PM gasses all boxes of tomatoes which are not labelled as "vine ripe". } \\
\text { - Tomato boxes are shipped to cover the market demand, and the surplus remains as inventory of the packinghouse. }\end{array}$} \\
\hline
\end{tabular}

415 Table 6. Scenario 1.1 at Level 1 of the tomato packing problem.

\begin{tabular}{|c|c|c|}
\hline \multicolumn{3}{|c|}{ Scenario 1.1: Plan the the harvesting day of matured tomatoes } \\
\hline Goal & \multicolumn{2}{|c|}{ Decide how many acres of matured tomatoes to harvest for each grower in each day of the present cycle } \\
\hline Actors & Main actor & Packinghouse management (PM) \\
\hline \multirow[t]{2}{*}{ Resources } & Physical resources & Acres of tomatoes. \\
\hline & $\begin{array}{l}\text { Information } \\
\text { resources }\end{array}$ & $\begin{array}{l}\text { For each grower: harvest capacity, acres of matured tomatoes for each day and yields of bins } \\
\text { of tomatoes per acre. Also: cost of tomatoes damaged due to delayed harvest, packing and } \\
\text { gassing capacity of the packing house. }\end{array}$ \\
\hline \multirow[t]{3}{*}{ Context } & \multicolumn{2}{|c|}{ - A grower may only harvest in a day up to their harvest capacity. } \\
\hline & \multicolumn{2}{|c|}{$\begin{array}{l}\text { - The number of bins of harvested tomatoes to pack from all growers should be less than the available gassing } \\
\text { capacity of the packinghouse for that day. }\end{array}$} \\
\hline & \multicolumn{2}{|c|}{$\begin{array}{l}\text { - The number of bins of harvested tomatoes to be packed per day should be less than the combined regular and } \\
\text { overtime packing capacity of the packinghouse. }\end{array}$} \\
\hline Episodes & \multicolumn{2}{|c|}{$\begin{array}{l}\text { - Considering the information resources available, the PM calculates, for each day in the present cycle and for each } \\
\text { grower, the number of acres to harvest of tomatoes matured of the previous and the present cycles. }\end{array}$} \\
\hline
\end{tabular}

416 Table 7. Scenario 1.2 at Level 1 of the tomato packing problem.

\begin{tabular}{lll}
\hline Scenario 1.2: & Harvest \\
\hline Goal & Harvest the tomatoes and take them to the packinghouse. \\
\hline Actors & Main actor $\quad$ Grower \\
\hline Resources & Physical resources & Acres of tomatoes; tomatoes; bins; packinghouse. \\
\cline { 2 - 3 } & $\begin{array}{l}\text { Information } \\
\text { resources }\end{array}$ & $\begin{array}{l}\text { Harvest capacity; acres of matured tomatoes for each day; number of acres to harvest each } \\
\text { day }\end{array}$ \\
\hline Context & - Tomatoes to be harvested are matured. \\
\hline Episodes & $\begin{array}{l}\text { - The grower cuts the tomatoes from the acres already matured that the PM decided to cut on the present day. } \\
\end{array}$ & - The grower places the tomatoes in bins. \\
& - The grower takes the bins to the packinghouse. \\
\hline
\end{tabular}


Table 8. Scenario 1.3 at Level 1 of the tomato packing problem.

\begin{tabular}{lll}
\hline Scenario 1.3: & Pack the harvested tomatoes \\
\hline Goal & Put the tomatoes in boxes to be transported. \\
\hline Actors & Main actors & Packinghouse personnel \\
\hline Resources & Physical resources & Bins of tomatoes; boxes; packinghouse. \\
\cline { 2 - 3 } & $\begin{array}{l}\text { Information } \\
\text { resources }\end{array}$ & $\begin{array}{l}\text { Gassing capacity; regular packing hours; regular packing hour cost; overtime packing hours; } \\
\text { overtime packing hour cost }\end{array}$ \\
\hline Context & - Packing occurs during regular packing hour plus overtime packing hours, which combined are at most 12 hours. \\
& - Regular packing hours are at most 8 hours a day, and overtime packing hours are at most 4 hours a day. \\
& - No more tomatoes may be packed once the packinghouse reaches the packing capacity \\
\hline
\end{tabular}

$420 \quad$ 4.2 Derived mathematical programming model

421 We show the derived mathematical programming model elements in separate tables according to 422 the rules applied. First, Table 9 shows the decision maker and indexes generated by applying Rules $4231-4$

424 Table 9. Derivation of decision maker and indexes.

\begin{tabular}{|c|c|c|c|}
\hline $\begin{array}{l}\text { Rule } \\
\text { Number }\end{array}$ & LEL model & Scenario model & $\begin{array}{l}\text { Mathematical } \\
\text { programming } \\
\text { model }\end{array}$ \\
\hline 1 & $\begin{array}{l}\text { Subject: Packinghouse } \\
\text { Management (PM) }\end{array}$ & $\begin{array}{l}\text { Scenario } 0 \\
\quad \text { Main actor PM }\end{array}$ & $\begin{array}{l}\text { Decision Maker } \\
P M\end{array}$ \\
\hline 2 & Object: Harvesting day & $\begin{array}{l}\text { Scenario } 0 \\
\text { Context } \\
\text { Temporal location } \\
\text { Decision period }\end{array}$ & Indexes \\
\hline 2 & Object: Maturity day & $\begin{array}{l}\text { Scenario } 0 \\
\text { Context } \\
\text { Temporal location } \\
\text { Other temporal vars }\end{array}$ & $j$ \\
\hline 3 & Subject: Grower & $\begin{array}{l}\text { Scenario } 0 \text { and } 1.2 \\
\text { Actor: Grower }\end{array}$ & $i$ \\
\hline
\end{tabular}

In the process of deriving the indexes, some scenarios' resources with multiple instances were considered as candidates on which to apply Rule 4. After that, the expert reviewed the relations among actors and resources but did not derive any sets because there are none restricted relations. Applying Rule 6 to the number of instances of the index for time period $t$ yielded the time horizon as the parameter $T$. The number of instances of the index for maturity day $j$ is the same parameter

$431 T$. The number of instances of the index for grower $i$ yielded parameter $K$. Other parameters came 432 from analyzing the attributes of scenarios' actors and resources. For example, the attribute acres of actor grower yielded parameter $H$. Rule 7 indicates that $H$ should be indexed by the indexes 
434 "related to it by the same notion". In this case, the expert inspected the notion of acres looking the 435 underlined terms (i.e., related elements) that were defined as indexes: $i$ for "grower", $j$ for

436 "maturity day" and $t$ for "harvesting time". However, the known values of acres are their grower 437 and their maturity day, but their harvesting time is unknown. Therefore, the indexes assigned to 438 the parameter are $i$ and $j$, and the parameter is $H_{i j}$. Other parameters were derived similarly. The 439 whole list of parameters appears in Table 10.

440 Table 10. Derivation of parameters.

\begin{tabular}{|c|c|c|c|}
\hline $\begin{array}{l}\text { Rule } \\
\text { Number }\end{array}$ & LEL model & Scenario model & $\begin{array}{l}\text { Mathematical } \\
\text { programming } \\
\text { model } \\
\text { parameter }\end{array}$ \\
\hline 6 & $\begin{array}{l}\text { Object: Harvesting day } \\
\text { Index: } t\end{array}$ & $\begin{array}{l}\text { Scenario } 0 \\
\text { Context } \\
\text { Temporal location } \\
\text { Decision period } \\
\end{array}$ & $T$ \\
\hline 6 & $\begin{array}{l}\text { Subject: Grower } \\
\text { Index: } i\end{array}$ & $\begin{array}{l}\text { Scenario } 0 \text { and } 1.2 \\
\text { Actor: Grower }\end{array}$ & $K$ \\
\hline 7 & $\begin{array}{l}\text { Subject: Grower } \\
\text { Attribute: Acres } \\
\text { Related indexes: } \\
\text { Grower } \quad(i), \\
\text { Maturity day }(j)\end{array}$ & $\begin{array}{l}\text { Scenario } 0 \text { and } 1.2 \\
\text { Actor: Grower } \\
\text { Attribute: Acres }\end{array}$ & $H_{i j}$ \\
\hline 7 & $\begin{array}{l}\text { Subject: Grower } \\
\text { Attr: Harvest capacity } \\
\text { Related indexes: } i\end{array}$ & $\begin{array}{l}\text { Scenario } 0 \text { and } 1.2 \\
\text { Actor: Grower } \\
\text { Attr: Harvest capacity }\end{array}$ & $U_{i}$ \\
\hline 7 & $\begin{array}{l}\text { Subject: Grower } \\
\text { Attr: Yields of bins } \\
\text { Related indexes: } i\end{array}$ & $\begin{array}{l}\text { Scenario } 0 \text { and } 1.2 \\
\text { Actor: Grower } \\
\text { Attr: Yields of bins }\end{array}$ & $b_{i}$ \\
\hline 7 & $\begin{array}{l}\text { Subject: Market } \\
\text { Attr: Market demand } \\
\text { Related indexes: } \\
\text { Harvesting day }(t)\end{array}$ & $\begin{array}{l}\text { Scenario } 0 \\
\text { Actor: Market } \\
\text { Attr: Market demand }\end{array}$ & $D_{t}$ \\
\hline 7 & $\begin{array}{l}\text { Object: Acres } \\
\text { Attr: Fraction of v.r.t. } \\
\text { Related indexes: - }\end{array}$ & $\begin{array}{l}\text { Scenario } 0 \\
\text { Resource: Acres } \\
\text { Attr: Fraction of v.r.t. }\end{array}$ & $\delta$ \\
\hline 7 & $\begin{array}{l}\text { Object: Packinghouse } \\
\text { Attr: Packing capacity } \\
\text { Related indexes: - }\end{array}$ & $\begin{array}{l}\text { Scenario } 0 \\
\text { Resource: Packinghouse } \\
\text { Attr: Packing capacity }\end{array}$ & $P$ \\
\hline 7 & $\begin{array}{l}\text { Object: Packinghouse } \\
\text { Attr: Gassing capacity } \\
\text { Related indexes: } t\end{array}$ & $\begin{array}{l}\text { Scenario } 0 \\
\text { Resource: Packinghouse } \\
\text { Attr: Gassing capacity }\end{array}$ & $G_{t}$ \\
\hline 7 & $\begin{array}{l}\text { Object: Packinghouse } \\
\text { Attr: Packing cost } \\
\text { Notion: Cost of } \\
\text { damaged tomato } \\
\text { Related indexes: - }\end{array}$ & $\begin{array}{l}\text { Scenario } 1.3 \\
\text { Resource: Packinghouse } \\
\text { Attr: Packing cost } \\
\text { Notion: Cost of damaged } \\
\text { tomato }\end{array}$ & $C$ \\
\hline 7 & $\begin{array}{l}\text { Object: Packinghouse } \\
\text { Attr: Packing cost } \\
\text { Notion: Inventory } \\
\text { holding cost } \\
\text { Related indexes: - }\end{array}$ & $\begin{array}{l}\text { Scenario } 1.3 \\
\text { Resource: Packinghouse } \\
\text { Attr: Packing cost } \\
\text { Notion: Inventory } \\
\text { holding cost }\end{array}$ & $C h$ \\
\hline
\end{tabular}




\begin{tabular}{|c|c|c|c|}
\hline 7 & $\begin{array}{l}\text { Object: Packinghouse } \\
\text { Attr: Packing cost } \\
\text { Notion: Shortfall cost } \\
\text { Related indexes: - }\end{array}$ & $\begin{array}{l}\text { Scenario } 1.3 \\
\text { Resource: Packinghouse } \\
\text { Attr: Packing cost } \\
\text { Notion: Shortfall cost }\end{array}$ & $C s$ \\
\hline 7 & $\begin{array}{l}\text { Object: Packinghouse } \\
\text { Attr: Packing cost } \\
\text { Notion: Regular } \\
\text { packing cost } \\
\text { Related indexes: - }\end{array}$ & $\begin{array}{l}\text { Scenario } 1.3 \\
\text { Resource: Packinghouse } \\
\text { Attr: Packing cost } \\
\text { Notion: Regular } \\
\text { packing cost }\end{array}$ & $\mathrm{Cr}$ \\
\hline 7 & $\begin{array}{l}\text { Object: Packinghouse } \\
\text { Attr: Packing cost } \\
\text { Notion: Overtime } \\
\text { packing cost } \\
\text { Related indexes: - }\end{array}$ & $\begin{array}{l}\text { Scenario } 1.3 \\
\text { Resource: Packinghouse } \\
\text { Attr: Packing cost } \\
\text { Notion: Overtime } \\
\text { packing cost }\end{array}$ & Co \\
\hline 7 & $\begin{array}{l}\text { Object: Packinghouse } \\
\text { Attr: Fraction of hour } \\
\text { needed to pack a bin } \\
\text { Related indexes: - }\end{array}$ & $\begin{array}{l}\text { Scenario } 0 \\
\text { Resource: Packinghouse } \\
\text { Attr: Fraction of hour } \\
\text { needed to pack a bin }\end{array}$ & $f$ \\
\hline 7 & $\begin{array}{l}\text { Object: Packinghouse } \\
\text { Attr: Fraction of tom. } \\
\text { ready after gassing } \\
\text { Related indexes: - }\end{array}$ & $\begin{array}{l}\text { Scenario } 0 \\
\text { Resource: Packinghouse } \\
\text { Attr: Fraction of tom. } \\
\text { ready after gassing }\end{array}$ & $\alpha$ \\
\hline
\end{tabular}

441

The next step was to derive the decision variables from the analysis of the attributes of scenarios' actors and resources, but this time, with unknown values. For example, the attribute acres of actor grower, with a certain maturity day and with an uncertain harvesting day. This attribute yielded decision variable $X$. Similar to the case for parameter $H$, to find the indexes for variable $X$ the expert looked at the underlined indexes in notion of acres, which are: $i$ for grower, $j$ for maturity day and $t$ for harvesting time, and the 3 of them are assigned to $X$ to yield $X_{i j t}$. Other decision variables were derived similarly by applying Rule $8\left(I_{t}, R_{t}, O_{t}, S_{t}\right)$, and appear in Table 11 . Further analysis on the scenarios and the context, caused the expert to split the decision variable $X_{i j t}$ in 2 variables: $X_{i j t}$ to refer to the acres matured on the present cycle and $L_{i j t}$ to refer to the acres matured on the last cycle. Additionally, 2 more decision variables were needed to represent the acres not harvested, both in the present cycle $\left(Y_{i j t}\right)$ and the past cycle $\left(A_{i j t}\right)$.

To define the objective function ${ }^{1}$, Rule 9 was applied. Then, the expert had to manually write the final equation:

\section{Minimize}


458 Table 11. Resulting decision variables.

\begin{tabular}{|c|c|c|c|}
\hline Rule & LEL model & Scenario model & $\begin{array}{l}\text { Mathematical } \\
\text { programming } \\
\text { model }\end{array}$ \\
\hline 8 & $\begin{array}{l}\text { Subject: Grower } \\
\text { Attribute: Acres } \\
\text { Rel. indexes: } i, j, t\end{array}$ & $\begin{array}{l}\text { Scenario } 0 \text { and } 1.2 \\
\text { Actor: Grower } \\
\text { Attr.: Acres }\end{array}$ & $X_{i j t}$ \\
\hline 8 & $\begin{array}{l}\text { Object: Packinghouse } \\
\text { Attr.: Inventory level } \\
\text { Related indexes: } t\end{array}$ & $\begin{array}{l}\text { Scenario } 0 \\
\text { Resource: Packinghouse } \\
\text { Attr.: Inventory level }\end{array}$ & $I_{t}$ \\
\hline 8 & $\begin{array}{l}\text { Object: Packinghouse } \\
\text { Attr.: Regular packing hours } \\
\text { Related indexes: } t\end{array}$ & $\begin{array}{l}\text { Scenario 0 } \\
\text { Resource: Packinghouse } \\
\text { Attr.: Regular packing hs }\end{array}$ & $R_{t}$ \\
\hline 8 & $\begin{array}{l}\text { Object: Packinghouse } \\
\text { Attr.: Overtime packing hours } \\
\text { Related indexes: } t\end{array}$ & $\begin{array}{l}\text { Scenario } 0 \\
\quad \text { Resource: Packinghouse } \\
\text { Attr.: Overtime packing hs }\end{array}$ & $O_{t}$ \\
\hline 8 & $\begin{array}{l}\text { Object: Market demand } \\
\text { Attribute: Shortfall } \\
\text { Related indexes: } t\end{array}$ & $\begin{array}{l}\text { Scenario } 0 \\
\text { Resource: Market demand } \\
\text { Attribute: Shortfall }\end{array}$ & $S_{t}$ \\
\hline- & Derived manually by the expert & $\begin{array}{l}\text { Scenario } 0 \text { and } 1.2 \\
\text { Actor: Grower. Attr.: Acres } \\
\quad \text { (matured on last cycle) }\end{array}$ & $L_{i j t}$ \\
\hline- & Derived manually by the expert & $\begin{array}{l}\text { Scenario } 0 \text { and } 1.2 \\
\text { Actor: Grower. Attr.: Acres } \\
\text { (matured present cycle not harvested) }\end{array}$ & $Y_{i j t}$ \\
\hline- & Derived manually by the expert & $\begin{array}{l}\text { Scenario } 0 \text { and } 1.2 \\
\text { Actor: Grower. Attr.: Acres } \\
\text { (matured on last cycle not harvested) }\end{array}$ & $A_{i j t}$ \\
\hline
\end{tabular}

460 Deriving the constraints was mostly handcrafted taking all the information available in the context

461 sentences of scenarios to create the corresponding equations, plus the addition new constraints to

462 balance quantities and make the mathematical programming model work. Constraints appear in

463 Table 12.

464 Table 12. Resulting constraints.

\begin{tabular}{|c|c|c|}
\hline Rule & Scenario model & Mathematical programming model \\
\hline 10 & $\begin{array}{l}\text { Scenario } 0 \text { \& } 1.1 \\
\text { Context sentence: A grower may only harvest in a day up } \\
\text { to his harvest capacity. }\end{array}$ & $\sum_{i=1}^{K} X_{i j t}+L_{i j t} \leq U_{i} \forall_{i t}$ \\
\hline 10 & $\begin{array}{l}\text { Scenario } 1.1 \\
\text { Context sntc: The number of bins of harvested tomatoes } \\
\text { to pack from all growers should be less than the gassing } \\
\text { capacity of the packinghouse for that day. }\end{array}$ & $\begin{array}{c}(1-\delta) \sum_{i=1}^{K} \sum_{t-j=0}^{T-1} X_{i j t} * b_{i}+ \\
\sum_{i=1}^{K} \sum_{t+T-j=1}^{T} L_{i j t} * b_{i} \leq G_{t} \forall_{t}\end{array}$ \\
\hline 10 & $\begin{array}{l}\text { Scenario } 1.1 \\
\text { Context sntc: The number of bins of harvested tomatoes } \\
\text { to be packed per day should be less than the combined } \\
\text { regular and overtime packing capacity of the packinghouse. }\end{array}$ & $\begin{array}{l}O_{t}+R_{t}-f \sum_{i=1}^{K} \sum_{t-j=0}^{T-1} X_{i j t} * b_{i}- \\
f \sum_{i=1}^{K} \sum_{T-j=1}^{T} L_{i j t} * b_{i}=0 \forall_{t}\end{array}$ \\
\hline
\end{tabular}




\begin{tabular}{|c|c|c|}
\hline 10 & $\begin{array}{l}\text { Scenario } 1.3 \\
\text { Context sntc: Packing occurs during regular packing hour } \\
\text { plus overtime packing hours, which are at most } 12 \text { hours. }\end{array}$ & $O_{t}+R_{t} \leq 12 \forall_{t}$ \\
\hline 10 & $\begin{array}{l}\text { Scenario } 1.3 \\
\quad \text { Context sntc: Regular packing hs. are at most } 8 \text { hours/day }\end{array}$ & $R_{t} \leq 8 \forall_{t}$ \\
\hline - & $\begin{array}{l}\text { Added by expert: balance the acres matured in the previous } \\
\text { cycle but not yet harvested }\end{array}$ & $A_{i j t}-A_{i j t-1}+L_{i j t}=0 \forall_{i j t}$ \\
\hline - & $\begin{array}{l}\text { Added by expert: balance the acres matured in the present } \\
\text { cycle but not yet harvested }\end{array}$ & $Y_{i j t}-Y_{i j t-1}+X_{i j t}=H_{i j} \forall_{i j t}$ \\
\hline - & $\begin{array}{l}\text { Added by expert: balance the end-of-period inventory level } \\
\text { (equal to the preceding end-of-period level + the quantity } \\
\text { of "vine ripe" tomatoes packed + the number of boxes of } \\
\text { tomatoes ready after gassing - the forecasted demand) }\end{array}$ & $\begin{array}{l}I_{t}-S_{t}-I_{t-1}+S_{t-1}-\delta \sum_{i=1}^{K} \sum_{t-j=0}^{T-1} X_{i j t} * b_{i}+ \\
\delta \sum_{i=1}^{K} \sum_{t-T-j=1}^{T} L_{i j t} * b_{i}=D_{t}+G_{t} \forall_{t}\end{array}$ \\
\hline - & $\begin{array}{l}\text { Added by expert: assure a continual flow of tomatoes to the } \\
\text { market. The mature green tomatoes to be packed should be } \\
\text { at least equal to a fraction } \alpha \text { of tomatoes ready on the day } \\
\text { of gassing. }\end{array}$ & $\begin{array}{c}(1-\delta) \sum_{i=1}^{K} \sum_{t-j=0}^{T-1} X_{i j t} * b_{i}+ \\
\sum_{i=1}^{K} \sum_{t+T-j=1}^{T} L_{i j t} * b_{i} \geq \alpha G_{t} \forall_{t}\end{array}$ \\
\hline
\end{tabular}

\section{Semantic mediawiki construction for the LEL and scenarios definition}

466 A domain ontology is proposed to attain the shared and agreed definition of a semantic model for

467 the LEL and scenarios. Moreover, ontology-based information retrieval allows us to formulate

468 queries based on our derivation rules, which will help in the semi-automatic derivation of 469 mathematical programming model elements. Finally, tool support is provided through a semantic 470 mediawiki constructed over the ontology, which allows for the knowledge building process of a 471 conceptual model and its derivation into math model elements.

\section{$472 \quad 5.1$ Ontology Model}

473 The proposed ontology is depicted in Figure 2. Thus, Subjects symbols are related to Scenario's 474 Actors while Objects symbols are related to Scenario's Resources. Moreover, Verbs symbols are 475 related to Scenario and Episode from Scenario's representation as they represent the activities or 476 actions that are realized. LEL symbols are represented by the Symbol element, that has two 477 properties: a notion and a list of behavioral responses. Thus, the notion property just contains has 478 relations with Subjects and Objects that represent attributes of the described Symbol. Since we 479 need to differentiate known attributes (parameters) from unknown ones (decision variables), the 480 has relation is in fact modeled as two separate relations: has known and has unknown. In turn, the 
behavioral response of a LEL's Symbol is represented using a relation to the Verbs that represent the actions were the Symbol participates, and therefore, its responsibilities. From the scenario's perspective, the element Scenario is represented by a property to define a title as plane text. The rest of the Scenario's properties are represented as relations with other model elements. Thus, there is a relation called bounded to a Context. There are two relations from Scenario to the Actor element called involves main actor and involves secondary actor, to represent the main and secondary actors of the Scenario respectively. Scenario also has a property called executed over, to related it with the Resources over which it is executed. The Scenario's episodes are described by the property performs related with the Episode elements. Finally,

490 Scenarios are connected by the property has to the Goal element.

491 In turn, a Context has a text property description and a has property related to a TemporalLoc that represents the temporal location of the scenarios with its properties for time-horizon, time_period and replanning_time_period. The Actor element has name and instance_number as properties, where the latter is used for the mathematical programming model derivation, to identify actors with more than one instance as indexes. Resource has a structure identical to Actor although their semantic meaning is completely different. The Episode element has a sentence that describes it and a relation described in that connects the Episodes to the parent Scenario. Moreover, a Goal has a property description and a relation optimize to an Optimization Goal. This Optimization Goal is not part of the original definition of scenarios but added for mathematical programming 500 model derivation purposes. It is described by two properties: Operation and TargetVariable to 501 define the $\max / \min$ operation for one particular variable as objective of the Scenario's Goal. 502 Finally, there is a Constraint element that could be related with Episode, Actor, Resource or 503 TemporalLoc elements by the property is restricted by. A Constraint is defined by the property 504 expression, which is applied on the corresponding elements. 


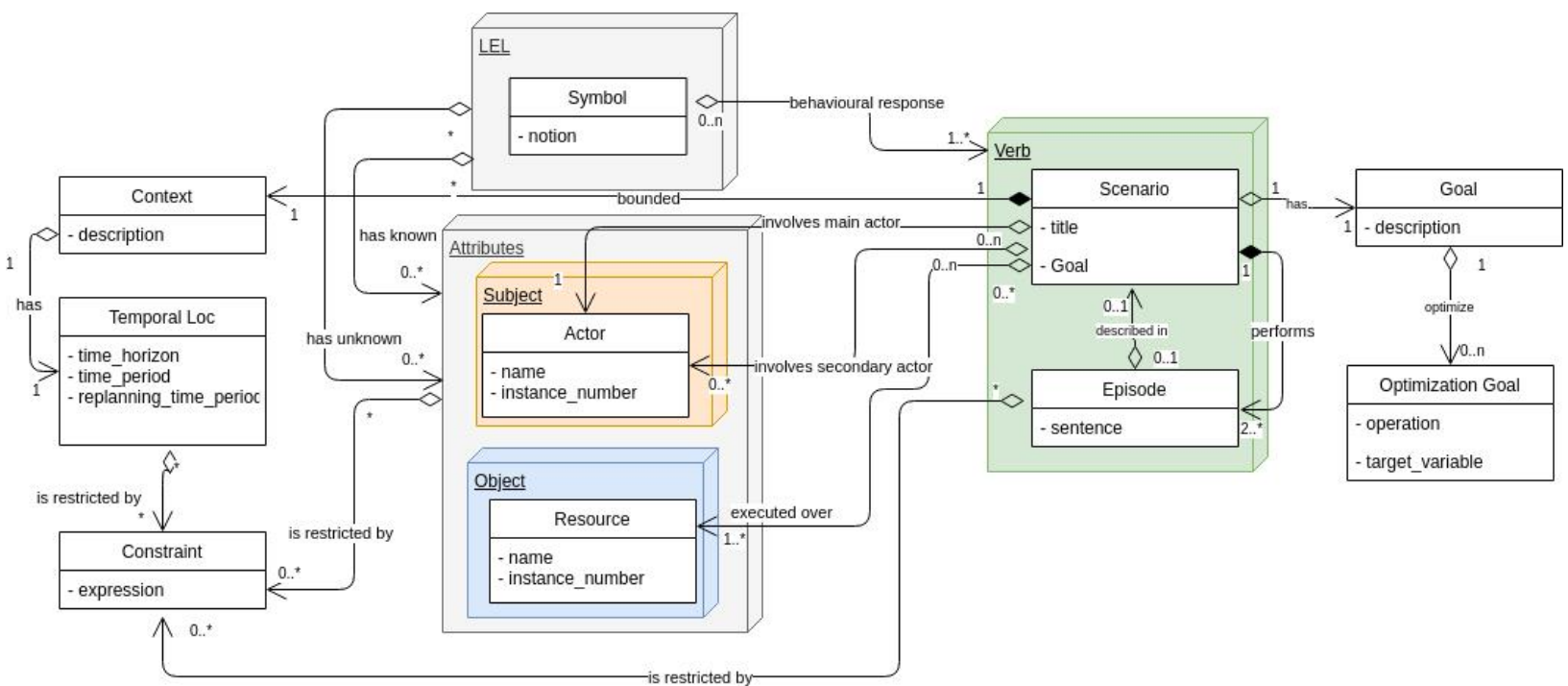

Fig. 2. The LEL and scenarios ontology.

509 The queries rely on the definition of a specific Scenario instance defined as Base Scenario. The

510 result of these queries will be used by the mathematical programming expert to obtain a

511 preliminary version of the final mathematical programming model, as explained before. Table 13

512 summarizes the queries, in a pseudo-code that makes them more readable.

513 Table 13. Queries based on each rule to derive potential mathematical programming model elements

\begin{tabular}{|c|c|c|}
\hline $\begin{array}{l}\text { Rule } \\
\text { Number }\end{array}$ & $\begin{array}{l}\text { Mathematical } \\
\text { model output }\end{array}$ & Semantic Query \\
\hline 1 & Decision Maker & Base Scenario involves main actor: ?Actor \\
\hline 2 & Index & $\begin{array}{l}\text { Base } \quad \text { Scenario } \\
\text { ?Context has: ?TemporalLoc ?time_period }\end{array}$ \\
\hline 3 & Index & $\begin{array}{l}\text { Scenario involves main actor: ?Actor } \\
\text { ?Actor instance_number }>1 \text { : ?Actor } \\
\text { Scenario involves secondary actor: ?Actor } \\
\text { ?Actor instance_number }>1 \text { : ?Actor }\end{array}$ \\
\hline 4 & Index & $\begin{array}{l}\text { Scenario executed over: ?Resource } \\
\text { ?Resource instance_number }>1: \text { ?Resource }\end{array}$ \\
\hline 5 & Set & $\begin{array}{l}\text { Symbol has known: ?Attribute } 1 \\
\text { Symbol has known: ?Attribute } 2 \\
\text { (?Attribute1 is restricted by: ?Constraint) == (?Attribute } 2 \text { is restricted by: } \\
\text { ?Constraint) } \\
\text { ?Attribute1, ?Attribute } 2\end{array}$ \\
\hline 6 & Parameter & $\begin{array}{l}\text { Scenario executed over: ?Resource } \\
\text { ?Resource instance_number }>1: \text { ?Resource instance_number } \\
\text { Scenario involves secondary actor: ?Actor } \\
\text { ?Actor instance_number }>1: \text { ?Actor instance_number }\end{array}$ \\
\hline
\end{tabular}




\begin{tabular}{lll}
\hline $\mathbf{7}$ & Parameter & (Actor has known: ?Attribute)+ (Resource has known: ?Attribute) \\
\hline $\mathbf{8}$ & Decision Variable & (Actor has unknown: ?Attribute)+ (Resource has unknown: ?Attribute) \\
\hline $\mathbf{9}$ & Objective function & $\begin{array}{l}\text { Base Scenario has: ?Goal } \\
\text { ?Goal optimize: ?Optimization Goal }\end{array}$ \\
\hline $\mathbf{1 0}$ & Constraint & Constraint
\end{tabular}

514

515

516

517

518

520

521

522

523

524

525

526

527

528

Rule 1 determines the decision maker by requesting the main Actor from the Base Scenario. Rule 2 determines the temporal index from the time period, accessing the Context of the Base Scenario through the bounded property, and from the Context, using the properties has to reach the properties of the Temporal Location. Rules 3 and 4 are also intended for deriving indexes. In these queries, all the instances of Actor and Resource in all the scenarios are collected by the properties involves main actor, involves secondary actor and executed over, and they are selected if the property instance_number is greater than 1 . Rule 5 determines relations among Actors and Resources that are candidates to become sets, specifically, if they appear in the same notion and are related with the same Constraint by the property is restricted by. Rule 6 derives parameters from the indexes obtained by rules 3 and 4, specifically, the number of instances described by the property instance_number. Rule 7 derives parameters from known Attributes of Actors and Resources. Particularly, this rule uses the property has known that belongs to Symbol elements representing Subjects (for Actors) and Objects (for Resources). Similarly, Rule 8 determines decision variables but using the property has unknown to denote the unknown Attributes. To define the optimization goal of the mathematical programming model, it is necessary to access to the Goal of the Base Scenario by the property has and subsequently, to its Optimization Goals by the property optimize. Finally, any other restriction for the model could be derived from the Constraint elements. 


\subsection{Mediawiki implementation}

535 We have built a semantic mediawiki in order to provide support for the collaborative construction 536 of a knowledge base. The wiki provides the capability of creating and editing articles by way of a 537 user-friendly interface guided by forms that will be used by stakeholders, analysts and 538 mathematical modelling experts. These forms are based on the ontology proposed for the LEL and 539 scenarios. Figure 3 shows a form to describe a Scenario. The figure shows that some attributes as 540 goal and context are plain text, while others are described with a kind of button or token. These 541 tokens describe relations to other elements of the model already created.

Edit Scenario: Plan the harvest and the packing of fresh tomatoes

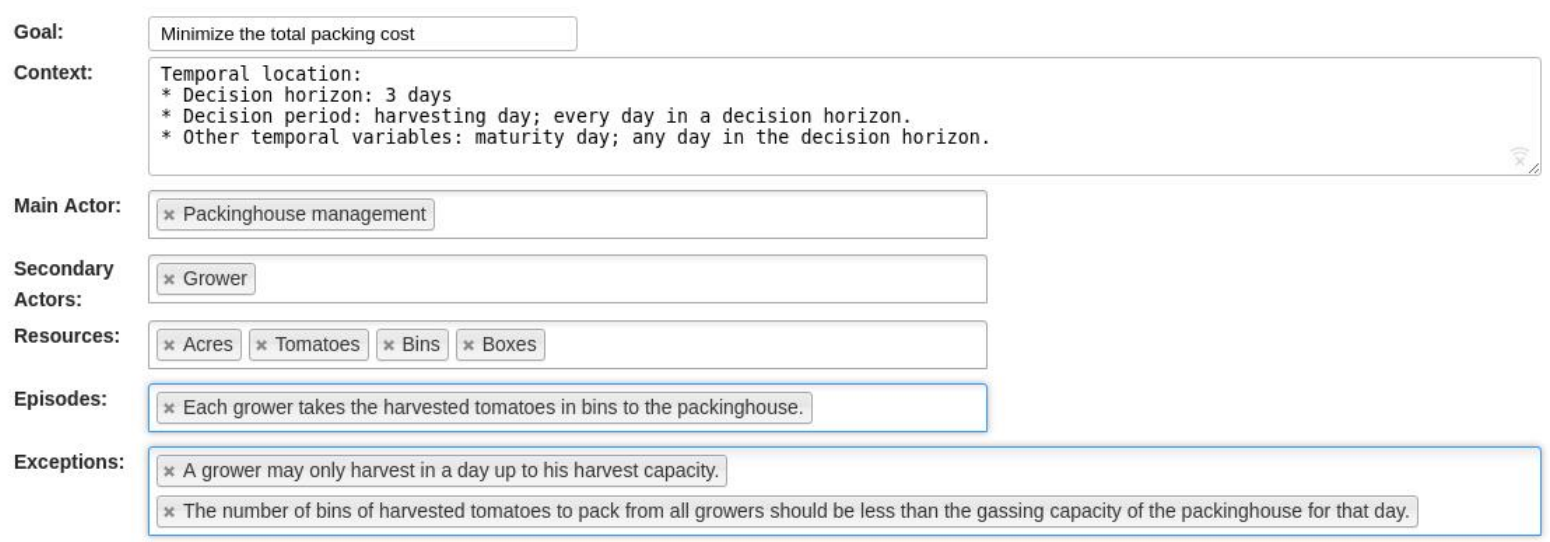

543 Fig. 3. Mediawiki form based on LEL and scenarios' ontology.

545 In turn, Figure 4 shows a form to navigate a Scenario. The wiki-links could be blue or red 546 describing whether the related article is already defined or not, respectively. 
Plan the harvest and the packing of fresh tomatoes

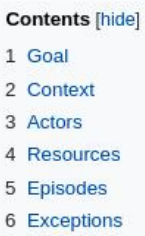

Goal [edit source]

Minimize the total packing cost

Context [ edit source]

Temporal location: Decision horizon: 3 days...

Actors [edit source]

Main Actor Packinghouse management

Secondary Actors Grower

Resources [ edit source]

Resources Acres, Tomatoes, Bins, Boxes

Fig. 4. Scenario's article.

550 Finally, the capability of application of ontologies as a semantic knowledge model allows to 551 implement the semantic queries described previously to semi-automatically derive mathematical 552 programming model elements from LEL + scenarios elements. Thus, once the knowledge base is 553 constructed, the mathematical modelling expert will be able to generate new articles with a 554 preliminary version of the mathematical programming model. Figures 5 displays an example, with 555 the article generated from the LEL and scenarios of the case study. Note that the support is not 556 completely automatic because the inference only allows for an approximation to the mathematical 557 programming model, and the expert is still needed to verify the correctness of the mediawiki 558 derivation and provide the algebraic form. 


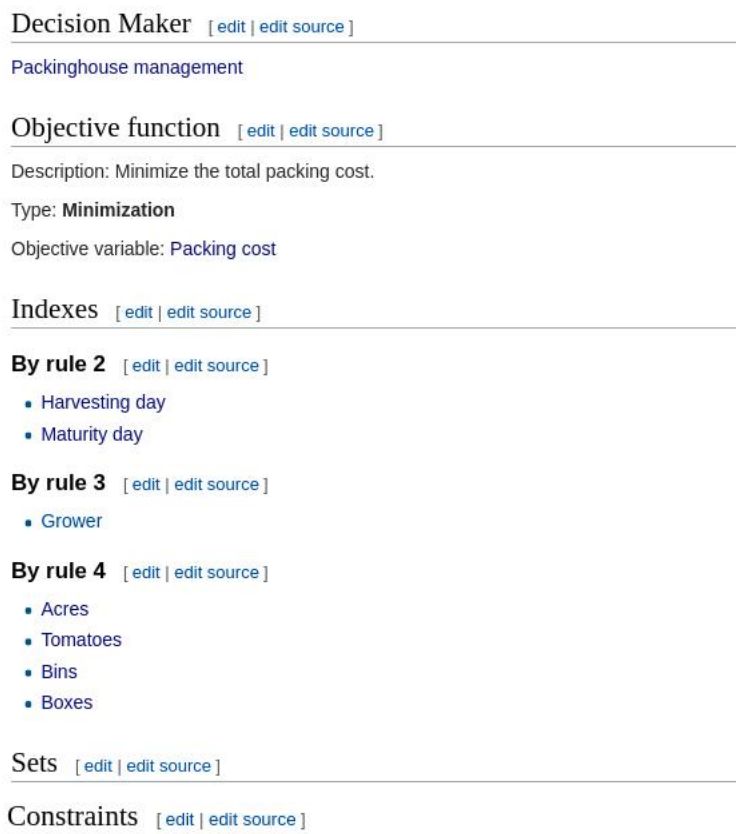

From contrains expresions: [edit | edit source]

- A grower may only harvest in a day up to his harvest capacity.

- The number of bins of harvested tomatoes to pack from all growers should be less than the gassing capacity of the packinghouse for that day.

- The number of bins of harvested tomatoes to be packed per day should be less than the combined regular and overtime packing capacity of the packinghouse.

- Packing occurs during regular packing hour plus overtime packing hours, which are at most 12 hours.

- Regular packing hs. are at most 8 hours/day

Expert's considerations [edit| edit source]

Rule 4

Remove indexes:

- Acres

- Tomatoes

- Bins

- Boxes

Rule 7

Packing cost:

- Cost of damaged tomato

- Inventoring holding cost

- Shortfall cost

- Regular packing cost

- Overtime packing cost

Rule 8

Acres:

561 Fig. 5. Article of mediawiki with automatic mathematical programming model derivation.

\section{6. Conclusions}

564 This paper has presented a novel methodology that connects the areas of requirements engineering

565 with conceptual_modelling in order to build mathematical programming models that capture the 566 business domain more effectively and completely. Specifically, the methodology has proposed for

567 the first time the use of the LEL and scenarios for creating a conceptual model of a domain from 
where a mathematical programming model can be derived. The construcion of the conceptual model invites the participation of all stakeholders, which is deficiency of other proposals for DSS construction in agriculture. In comparison with other approaches for conceptual mathematical modelling, this article provides further tool-supported guidence about how to obtain the problem

572 definition and how to derive a mathematical programming model from a precise specification in 573 terms of derivation rules, as opposed to relying on mere textual descriptions or in the modeler's ability. Moreover, we have proposed an ontology that provides the basis for a semantic mediawiki that serves both, sharing knowledge of the conceptual domain model among the different stakeholders, as well as semi-automating the derivation of the mathematical programming model.

577 The usefulness of this proposal can be understood from several perspectives: research, academic 578 and managerial. From the research and academic points of view, we may highlight the main contributions as follows: (i) it provides a novel step-by-step methodology based on the LEL and scenarios that allows both: to obtain the required information to derive the definition part of a mathematical programming model, and to define the optimization problems that constitute the

582 modelling part of the model; (ii) our approach provides a structure to the problem that allows to 583 identify the elements of the problem clearly; (iii) using the LEL and scenarios to create a conceptual model iteratively and incrementally in collaboration with stakeholders allows applying an agile development approach to mathematical modelling; (iv) the use of LEL and scenarios

586 provides traceability from the requirements to the mathematical programming model 587 implementation to cope with possible changes of requirements and a better understanding of their 588 impact on the model; and (v) the process of creating a conceptual model with LEL + scenarios 589 also generates a complete specification of requirements for a potential model-based DSS. 590 Regarding the managerial perspective, we believe that the ease of use and good expressiveness of 591 the proposed methodology will facilitate the implementation of mathematical programming 592 models in agriculture, as well as provide new tools for teaching mathematical programming and 
stochastic programming and fuzzy mathematical programming.

Acknowledgments. This work was supported by the European Commission, project H2020RUC-APS, grant number H2020-MSCA-RISE-2015-691249; and the Argentinian National Agency for Scientific and Technical Promotion (ANPCyT), grant number PICT-2015-3000.

601

602

603

604

605

606

607

608

609

610

611

612

613

614

615

616

617

618

619

620

621

622

623

624

625

626

627

628

629

630

631

632

633

634

635

\section{References}

Alemany, M., Ortiz, A. \& Fuertes-Miquel, V.S. (2018). A decision support tool for the order promising process with product homogeneity requirements in hybrid Make-To-Stock and Make-To-Order environments. Application to a ceramic tile company. Computers \& Industrial Engineering 122: 219-234.

Alemany, M.M.E., Alarcón, F., Lario, F.C. \& Boj, J.J. (2011). An application to support the temporal and spatial distributed decision-making process in supply chain collaborative planning. Computers in Industry 62: 519-540.

Alemany, M.M.E., Lario, F.C., Ortiz, A. \& Gómez, F. (2013). Available-To-Promise modeling for multi-plant manufacturing characterized by lack of homogeneity in the product: An illustration of a ceramic case. Applied Mathematical Modelling 37(5): 3380-3398.

Alemany, M.M.E., Pérez Perales, D., Alarcón, F. \& Boza, A. (2007). Planificación Colaborativa para Redes de Suministro-Distribución (RdS/D) mediante programación matemática en entornos distribuidos. In Int. Conference on Industrial Engineering \& Industrial Management.

Alexander, I. \& Maiden, N. (2004). Scenarios, stories, and use cases: the modern basis for system development. Computing Control Engineering Journal 15(5): 24-29.

Armengol, A., Mula, J., Díaz-Madroñero, M. \& Pelkonen, J. (2015). Conceptual model for associated costs of the internationalisation of operations. Lecture Notes in Management and Industrial Engineering 181-188.

Baraniuk, R., Burrus, C., Johnson, D. \& Jones, D. (2004). Sharing knowledge and building communities in signal processing. IEEE Signal Processing Magazine 21(5): 10-16.

Behzadi, G., O’Sullivan, M.J., Olsen, T.L. \& Zhang, A. (2018, September 1). Agribusiness supply chain risk management: A review of quantitative decision models. Omega (United Kingdom). Elsevier Ltd.

Breitman, K.K. \& Leite, J.C.S.P. (2003). Ontology as a requirements engineering product. In Proceedings of the IEEE Int. Conference on Requirements Engineering (RE).

Cid-Garcia, N.M. \& Ibarra-Rojas, O.J. (2019). An integrated approach for the rectangular delineation of management zones and the crop planning problems. Computers and Electronics in Agriculture 164.

Cysneiros, L.M. \& Leite, J.C.S.P. (2001). Using the language extended lexicon to support nonfunctional requirements elicitation. In Proceedings of the Workshops de Engenharia de Requisitos, Wer'01. Buenos Aires, Argentina.

Dominguez-Ballesteros, B., Mitra, G., Lucas, C. \& Koutsoukis, N.S. (2002). Modelling and solving environments for mathematical programming (MP): A status review and new 
directions. Journal of the Operational Research Society 53(10 SPEC.): 1072-1092. Retrieved from https://doi.org/10.1057/palgrave.jors.2601361

Esteso, A., Alemany, M., Ortiz, A. \& Peidro, D. (2018). A multi-objective model for inventory and planned production reassignment to committed orders with homogeneity requirements. Computers \& Industrial Engineering 124: 180 - 194.

Esteso, A., Alemany, M.M.E. \& Ortiz, A. (2018). Conceptual framework for designing agri-food supply chains under uncertainty by mathematical programming models. International Journal of Production Research 56(13): 4418-4446.

Geisser, M. \& Hildenbrand, T. (2006). A method for collaborative requirements elicitation and decision-supported requirements analysis. In R. G. Ochoa S.F. (ed.), Advanced software engineering: expanding the frontiers of software technology. Boston, MA: Springer.

Giannoccaro, I. \& Pontrandolfo, P. (2001). Models for Supply Chain Management : A Taxonomy. In Production and Operations Management 2001.Conference POMS mastery in the new millennium. Orlando, FL, USA.

Gil, G.D., Figueroa, D.A. \& Oliveros, A. (2000). Producción del LEL en un dominio técnico. Informe de un caso. In Proceedings of the Workshops de Engenharia de Requisitos, Wer'00. Rio de Janeiro, Brazil.

Grillo, H., Alemany, M.M.E., Ortiz, A. \& Fuertes-Miquel, V.S. (2017). Mathematical modelling of the order-promising process for fruit supply chains considering the perishability and subtypes of products. Applied Mathematical Modelling 49: 255-278.

Grossmann, I. (2005). Enterprise-wide optimization: A new frontier in process systems engineering. American Institute of Chemical Engineers 51(7): 1846-1857.

Gruber, T. (1993). A translation approach to portable ontology specifications. Knowledge Acquisition 5(2): 199-220.

Gruber T. (1995). Toward principles for the design of ontologies used for knowledge sharing. International Journal of Human-Computer Studies 43(43): 907-928.

Hernández, J.E., Mula, J., Ferriols, F.J. \& Poler, R. (2008). A conceptual model for the production and transport planning process: An application to the automobile sector. Computers in $\begin{array}{llll}\text { Industry 59(8): } & 842-852 . & \text { Retrieved }\end{array}$ https://www.sciencedirect.com/science/article/pii/S0166361508000778

Jain, R., Malangmeih, L., Raju, S.S., Srivastava, S.K., Immaneulraj, K. \& Kaur, A.P. (2018). Optimization techniques for crop planning: A review. Indian Journal of Agricultural $\begin{array}{llll}\text { Sciences } & 88(12): & \text { Retrieved } & \text { 1826-1835. from }\end{array}$ https://www.researchgate.net/publication/329736318

Kaplan, G., Hadad, G., Doorn, J. \& Leite, J.C.S.P. (2000). Inspección del léxico extendido del lenguaje. In Proceedings of theWorkshops de Engenharia de Requisitos, Wer'00. Rio de Janeiro, Brazil.

Laporti, V., Borges, M.R.S. \& Braganholo, V. (2009). Athena: A collaborative approach to requirements elicitation. Computers in Industry 60(6): 367-380.

Leite, J.C.S.P. \& Franco, A.P.M. (1993). A strategy for conceptual model acquisition. In Proceedings of IEEE International Symposium on Requirements Engineering, 1993. San Diego, California: IEEE Computer Society Press.

Leite, J.C.S.P., Hadad, G., Doorn, J. \& Kaplan, G. (2000). A Scenario Construction Process. Requirements Engineering Journal 5(1): 38-61. Retrieved from http://link.springer.com/article/10.1007/PL00010342

Lenat, D.B. (1995). CYC: A large-scale investment in knowledge infrastructure. Communications of the ACM 38(11): 33-38.

Lesh, R, Landau, M. \& Hamilton, E. (1983). Conceptual models in applied mathematical problem solving research. In R. Lesh and M. Landau (ed.), Acquisition of Mathematics Concepts and 
Processes. NY: Academic Press.

686

687

688

689

690

691

692

693

694

695

696

697

698

699

700

701

702

703

704

705

706

707

708

709

710

711

712

713

714

715

716

717

718

719

720

721

722

723

724

725

726

727

728

729

730

731

732

733

Lesh, Richard. (1981). Applied mathematical problem solving. Educational Studies in Mathematics 12(2): 235-264. Retrieved from https://doi.org/10.1007/BF00305624

Lezoche, M., Yahia, E., Aubry, A., Panetto, H. \& Zdravković, M. (2012). Conceptualising and structuring semantics in cooperative enterprise information systems models. Computers in $\begin{array}{llll}\text { Industry } & 63(8): & \text { 775-787. } & \text { Retrieved }\end{array}$ https://www.sciencedirect.com/science/article/pii/S016636151200125X

Liu, L., Wang, H. \& Xing, S. (2019). Optimization of distribution planning for agricultural products in logistics based on degree of maturity. Computers and Electronics in Agriculture 160: $1-7$.

Miller, G.A. (1995). WordNet: a lexical database for English. Communications of the ACM 38(11): 39-41.

Miller, W.A., Leung, L.C., Azhar, T.M. \& Sargent, S. (1997). Fuzzy production planning model for fresh tomato packing. International Journal of Production Economics 53(3): 227-238. Retrieved from http://linkinghub.elsevier.com/retrieve/pii/S0925527397001102

Mir, S.A., Qasim, M., Arfat, Y., Mubarak, T., Bhat, Z.A., Bhat, J.A., ... Sofi, T.A. (2015). Decision support systems in a global agricultural perspective-a comprehensive review. Journal of Agriculture Sciences 7(1): 403-415.

Moskaliuk, J., Kimmerle, J. \& Cress, U. (2009). Wiki-supported learning and knowledge building: effects of incongruity between knowledge and information. Journal of Computer Assisted Learning 25(6): 549-561.

Mula, J., Poler, R., García-Sabater, J.P. \& Lario, F.C. (2006). Models for production planning under uncertainty: A review. International Journal of Production Economics 103(1): 271285. Retrieved from https://www.sciencedirect.com/science/article/pii/S0925527306000041

Mula, Josefa, Peidro, D., Díaz-Madroñero, M. \& Vicens, E. (2010). Mathematical programming models for supply chain production and transport planning. European Journal of Operational Research 204(3): 377-390. Retrieved from http://dx.doi.org/10.1016/j.ejor.2009.09.008

Mundi, I., Alemany, M., Boza, A. \& Poler, R. (2013). A model-driven decision support system for the master planning of ceramic supply chains with non-uniformity of finished goods. Studies in Informatics and Control 22(2): 153-16. Retrieved from https://doi.org/10.24846/v22i2y201305

Munir, K. \& Sheraz Anjum, M. (2018). The use of ontologies for effective knowledge modelling and information retrieval. Applied Computing and Informatics 14(2): 116-126. Retrieved from https://www.sciencedirect.com/science/article/pii/S2210832717300649\#b0035

Oliveira, A. de P.A., Leite, J.C.S. do P., Cysneiros, L.M. \& Cappelli, C. (2007). Eliciting MultiAgent Systems Intentionality: from Language Extended Lexicon to i* Models. In XXVI International Conference of the Chilean Society of Computer Science (SCCC'07). IEEE. Retrieved from http://ieeexplore.ieee.org/document/4396976/

Pérez, D., Lario, F.C. \& Alemany, M.M.E. (2010). Descripción detallada de las Variables de Decisión en Modelos basados en Programación Matemática en un contexto de Planificación Colaborativa de una Red de Suministro/Distribución (RdS/D). In 4th Int. Conf. on Industrial Engineering and Industrial Management; XIV Congreso de Ingeniería de Organización. Donostia - San Sebastián.

Pérez Perales, D., Lario, F.C., Alemany, M.M.E. \& Hernández, J. (2012). Framework for Modelling the Decision. International Journal of Decision Support System Technology 4(2): 59-77. Retrieved from http://services.igiglobal.com/resolvedoi/resolve.aspx?doi=10.4018/jdsst.2012040104

Pesic, M. \& van der Aalst, W.M.P. (2005). Towards a reference model for work ditstribution in workflow management systems. In \& M. N. E. Kindler (ed.), Proceedings of the First 
International Workshop on Business Process Reference Models (BPRM,05). Nancy: University Henri Poincaré.

Raghunathan, S. (1996). A structured modeling based methodology to design decision support systems. Decision Support Systems 17(4): 299-312.

Saranya, S. \& Amudha, T. (2017). Crop planning optimization research - A detailed investigation. In 2016 IEEE International Conference on Advances in Computer Applications, ICACA 2016. Institute of Electrical and Electronics Engineers Inc.

Schneeweiss, C. (2003a). Distributed decision making in supply chain management. International Journal of Production Economics 84(1): 71-83. Retrieved from https://www.sciencedirect.com/science/article/pii/S092552730200381X

Schneeweiss, C. (2003b). Distributed decision making — a unified approach. European Journal of Operational Research 150(2): 237-252. Retrieved from https://www.sciencedirect.com/science/article/abs/pii/S0377221702005015

Schön, E.-M., Thomaschewski, J. \& Escalona, M.J. (2017). Agile Requirements Engineering: A systematic literature review. Computer Standards \& Interfaces 49: 79-91. Retrieved from https://www.sciencedirect.com/science/article/abs/pii/S0920548916300708

Shapiro, J.F. (1993). Chapter 8 Mathematical programming models and methods for production planning and scheduling. Handbooks in Operations Research and Management Science 4: 371-443. $\quad$ Retrieved https://www.sciencedirect.com/science/article/abs/pii/S0927050705801884

Siau, K. (2004). Evaluating the Usability of A Group Support System Using Co-Discovery. Journal of Computer Information Systems 44(2): 17-28. Retrieved from https://www.tandfonline.com/doi/abs/10.1080/08874417.2004.11647563

Soto-Silva, W.E., Nadal-Roig, E., González-Araya, M.C. \& Pla-Aragones, L.M. (2016, June 1). Operational research models applied to the fresh fruit supply chain. European Journal of Operational Research. Elsevier B.V.

Swartout, B., Patil, R., Knight, K. \& Russ, T. (1996). Toward distributed use of large-scale ontologies. In Proc. of the Tenth Workshop on Knowledge Acquisition for Knowledge-Based Systems. Banff, Canada.

Udias, A., Pastori, M., Dondeynaz, C., Carmona Moreno, C., Ali, A., Cattaneo, L. \& Cano, J. (2018). A decision support tool to enhance agricultural growth in the Mékrou river basin (West Africa). Computers and Electronics in Agriculture 154: 467-481.

Vicens, E., Alemany, M.., Andrés, C. \& Guarch, J.. (2001). A design and application methodology for hierarchical production planning decision support systems in an enterprise integration context. International Journal of Production Economics 74(1-3): 5-20. Retrieved from https://www.sciencedirect.com/science/article/pii/S0925527301001037

Young, R. (2004). The Requirements Engineering Handbook. Artech HouseISBN: 978-1-58053266-2. 